Pacific Northwest

National Laboratory

Operated by Battelle for the

U.S. Department of Energy

\section{Asian Tracer Experiment and Atmospheric Modeling (TEAM) Project: \\ Draft Field Worle Plan for the Asian \\ Long-Range Tracer Experiment}

K. J. Allwine

J. E. Flaherty

August 2007

Prepared for the U.S. Department of Energy

under Contract DE-AC05-76RL01830

U.S. DOE National Nuclear Security Administration NA-46

Office of International Emergency Management and Cooperation 


\title{
DISCLAIMER
}

This report was prepared as an account of work sponsored by an agency of the United States Government. Neither the United States Government nor any agency thereof, nor Battelle Memorial Institute, nor any of their employees, makes any warranty, express or implied, or assumes any legal liability or responsibility for the accuracy, completeness, or usefulness of any information, apparatus, product, or process disclosed, or represents that its use would not infringe privately owned rights. Reference herein to any specific commercial product, process, or service by trade name, trademark, manufacturer, or otherwise does not necessarily constitute or imply its endorsement, recommendation, or favoring by the United States Government or any agency thereof, or Battelle Memorial Institute. The views and opinions of authors expressed herein do not necessarily state or reflect those of the United States Government or any agency thereof.

\author{
PACIFIC NORTHWEST NATIONAL LABORATORY \\ operated by \\ BATTELLE \\ for the \\ UNITED STATES DEPARTMENT OF ENERGY \\ under Contract DE-ACO5-76RL01830
}

Printed in the United States of America
Available to DOE and DOE contractors from the
Office of Scientific and Technical Information,
P.O. Box 62, Oak Ridge, TN 37831-0062;
ph: (865) 576-8401
fax: (865) 5765728
email: reports@adonis.osti.gov

\author{
Available to the public from the National Technical Information Service, \\ U.S. Department of Commerce, 5285 Port Royal Rd., Springfield, VA 22161 \\ ph: (800) 553-6847 \\ fax: (703) 605-6900 \\ email: orders@nits.fedworld.gov \\ online ordering: http://www.ntis.gov/ordering.htm
}




\title{
Asian Tracer Experiment and Atmospheric Modeling (TEAM) Project: \\ Draft Field Work Plan for the Asian Long-Range Tracer Experiment
}

\author{
K. J. Allwine \\ J. E. Flaherty
}

August 2007

Prepared for the U.S. Department of Energy

under Contract DE-AC05-76RL01830

U.S. DOE National Nuclear Security Administration NA-46

Office of International Emergency Management and Cooperation

Pacific Northwest National Laboratory

Richland, Washington 99352 



\section{Summary}

An important element for effective emergency response to an event involving harmful airborne materials is having validated atmospheric dispersion models that can track and forecast the path of airborne materials even as far as several thousand kilometers. Four countries have joined through the Asian Tracer Experiment and Atmospheric Modeling (TEAM) Project to design and conduct an Asian long-range $(\sim 3000-\mathrm{km})$ tracer study. This study will provide critically-needed ground-truth dispersion data to validate atmospheric dispersion models applicable to eastern Asia (atmospheric transport from central China eastward across South Korea to central Japan). The partnering countries in the TEAM project are China, Japan, South Korea, and the United States. The lead organizations within each country are the China Institute for Radiation Protection (CIRP), the Japan Atomic Energy Agency, the Korean Atomic Energy Research Institute, and the U.S. Department of Energy's National Nuclear Security Administration, Office of International Emergency Management and Cooperation.

Long-range tracer experiments are complex and require meticulous and detailed planning to be successful. Experts in tracer sampling and chemical analysis are required to accurately measure perfluorocarbon tracers (PFTs) to global background levels of a few parts tracer in $10^{15}$ parts air by volume. Only two long-range tracer studies with transport distances over $2000 \mathrm{~km}$ have been conducted to date. One study was the Across North America Tracer Experiment (ANATEX) conducted in 1987 and the second was the European Tracer Experiment (ETEX) conducted during 1994. These tracer experiments were complex and required considerable planning. ETEX was more than two years in planning and preparation.

This report provides an experimental plan for the proposed tracer study and gives optimal times of year to conduct the study, meteorological measurements needed, proposed tracer-release amounts and locations, proposed tracer-sampling locations, and the proposed durations of tracer releases and subsequent sampling. Also given are the activities necessary to prepare for the study and the schedule for completing the preparation activities leading to conducting the actual field operations. This report is intended to provide the TEAM members with the information necessary for planning and conducting the Asian long-range tracer study. The experimental plan is proposed, at this time, to describe the efforts necessary to conduct the Asian long-range tracer study, and the plan will undoubtedly be revised and refined as the planning goes forward over the next year.

At this time, the critical tracer sampling resources needed ( $\sim 210$ samplers) to conduct the Asian tracer study are not available in any TEAM country. Some sampling resources are available (e.g., Japan has 40 samplers, and the United States has 40 samplers), yet as in the case of the United States, even the available samplers have seen many years of service and should be replaced. Because of the complexity of a continental-scale tracer study and the importance of providing accurate (within 10\%) concentrations, it is imperative for the success of this unique study to have new and proven sampling equipment available for the field operations. Brookhaven National Laboratory (BNL), the U.S. experts in PFT technology with over 30 years of experience, has developed and been testing a prototype, next-generation PFT sampler. Using this prototype sampler design for the Asian study will help make sure that the proposed study is successful. BNL will make their sampler design and expertise available to TEAM partners who may need new tracer samplers. 
Two additional key components for making sure that the tracer study is successful are the dependability and robustness of the tracer-release equipment and the tracer analytical equipment. A new well-proven tracer release method (using a spinning porous cup atomizer) developed by BNL could be used in the Asian study and dependably provide the estimated 100 kilograms per hour of tracer for the proposed two 12-hour-long releases. The two PFTs proposed to be released are perfluoromethylcyclopentane (PMCP) and perfluoromethylcyclohexane (PMCH) or perfluoro-1,2dimethylcyclohexane (oc-PDCH) and perfluorotrimethylcyclohexane (PTCH). PMCP/PMCH have been used more often in tracer studies and require a shorter chemical analysis time, whereas oc- $\mathrm{PDCH}$, and especially PTCH, have not been used as much in tracer studies and require a longer analysis time. The benefit of using oc-PDCH/PTCH instead of $\mathrm{PMCP} / \mathrm{PMCH}$ is that the former pair have a much lower background level than the later (a factor of 10 lower), thus allowing for more measurement range at the $3000-\mathrm{km}$ distance or a lower release rate with the same measurement range.

Gas chromatography using an electron capture detector (GC-ECD) is the analytical method of choice for PFTs. It is important for the success of the proposed Asian long-range study that the analytical method and coupled sampler handling equipment be dependable and accurate and can operate in an automatic or semi-automatic mode. After completing the field study, a total of nearly 6000 samples will need to be chemically analyzed using GC-ECD systems fitted with sample-handling equipment. To complete the chemical analyses in a timely fashion, TEAM partners may need to upgrade current analytical capabilities or purchase new capabilities.

Trajectory and dispersion analysis by TEAM partners indicates that the best times of year for easterly transport from central China to South Korean and on to central Japan are early spring (March-April) and late fall (November-December). The most favorable time of year considering field logistics efforts (e.g., samplers' deployment and operations, and release operations) is during the spring when the temperatures are warmer as compared to the fall. The average high and low temperatures in Taiyuan, China, are 19 and $4^{\circ} \mathrm{C}$ during April compared to 2 and $-10^{\circ} \mathrm{C}$ during December. Field operations can certainly be conducted during the colder December temperatures, but all else being equal, equipment deployment during the warmer April temperatures could result in quicker and easier deployment and result in potentially fewer battery failures on tracer samplers.

CIRP proposed Yinchuan as the release location in central China. The transport distance from Yinchuan to central Japan is $\sim 3000 \mathrm{~km}$. A tracer sampling network of 167 samplers is proposed giving the needed coverage from Yinchuan to central Japan. A polar sampling grid is proposed with samplers on arcs spaced at approximately every $250 \mathrm{~km}$ and samplers on radials spaced every 5 degrees over a 90degree sector approximately centered on a line from Yinchuan to central Japan. The proposed distribution of samplers is 122 in China, 9 in the Yellow Sea, 9 in the South China Sea, 5 in South Korea, 18 in Japan, and 4 in the Sea of Japan. Those sampling locations over water are identified simply to give some recommended locations where buoy-borne, ship-borne, or airborne sampling may occur, provided these resources are available. Quality assurance considerations dictate the need for duplicate, control, and blank samplers. Consequently, the total number of PFT samplers needed for the Asian tracer study is 210. The approximate distribution of samplers (including quality assurance samplers) by a partner country is $\sim 80$ for China, $\sim 30$ for Japan, $\sim 10$ for South Korea, and $\sim 90$ for the United States. This distribution assumes potential over-water samplers to be primarily those of the Chinese and United States with Sea of Japan samplers deployed by Japan. Of course, this distribution will likely change as the 
planning progresses, and resources for over-water deployment (e.g., buoy-borne, ship-borne, and airborne) are identified and allocated.

A reasonable schedule for a successful Asian long-range tracer study is to conduct the study beginning on April 1, 2009, with field set-up and meteorological forecasting efforts beginning by midMarch 2009. Conducting the tracer study during April 2009 would allow for all the needed equipment to be fabricated and fully tested, the PFT tracer to be ordered, received, and validated for purity, and for preliminary field exercises to be conducted for testing the forecast team and for establishing background air concentrations. Another time-consuming effort that must be accomplished well before the planned April 2009 field study is to identify all the sampling locations. Every desired sampling location must be visited and a specific sampler position identified. With the small battery-powered samplers, often the easiest and most secure locations are to suspend the samplers from pre-installed hangers on existing poles. Installing the samplers at least 3 meters above the surface keeps them out of the reach of the local public.

The first critical step in accomplishing the Asian tracer study is the decision to go forward and the allocation of funding and engaging investigators. This should be done no later than October-November 2007 so long-lead-time activities can begin and preliminary spring 2008 field activities can be conducted. The important activities to be conducted beginning mid-March 2008 and continuing through to the end of April 2008 are to conduct background PFT measurements throughout the study region and to exercise the meteorological forecast team and evaluate their performance in predicting desirable release and sampling periods. The field director and field management team should also be in place before spring 2008 since the ultimate "go/no-go" decision is made by the field director with input from the field management team. The performance of the field management team with the critical input from the meteorological forecast team will be evaluated based on results of the spring 2008 preliminary exercise where the April 1 through 31,2008 , period will be treated as the "real study period" during which two tracer release and sampling efforts ( 5 to 7 days each) must be conducted.

The long-lead-time efforts needed to accomplish the Asian tracer study are:

- fabricate and test the $\sim 210$ new tracer samplers needed

- order, receive, and verify the purity of the two PFTs to be released

- procure, test, and verify the new GC-ECD analytical systems needed

- establish specific locations of tracer samplers and deployment methods, especially for over-water samplers.

In summary, many steps must be accomplished to successfully conduct the unique Asian long-range tracer study and provide accurate tracer concentrations across East Asia to validate emergency-response dispersion models. It is also critical for the success of the study for all the TEAM partners to have welldefined responsibilities and ready avenues of communication. Many details must be refined before conducting the study in April 2009 and before pre-study field activities during 2008, including a PFT background study and selection of sampling sites.

Section 1 of this report introduces the project and provides information about the scope of the project as well as important considerations. Section 2 explains the details of the proposed study, including the study region, the study period, the choice of tracers, and plans for tracer release. Detailed plans are provided for tracer sampling and meteorological measurements. Section 3 discusses additional important 
considerations that will need to be addressed as the planning for the study progresses, including organizational and administrative activities and critical activities associated with pre-preparation plans. Appendix A provides a map projection of the area targeted for the study, and Appendix B discusses the climatology of the study region. Appendix $\mathrm{C}$ discusses issues involved in distinguishing tracer measurements from global background concentrations that contain released tracer, Appendix D describes the simple Gaussian Puff model with relevant equations, and Appendix E provides time series plots of surface and upper air winds for five weather stations in China and one in Japan for April and December 2003. 


\section{Acronyms}

ANATEX Across North America Tracer Experiment

ATP

Asian TEAM Project

BNL Brookhaven National Laboratory

CIRP China Institute for Radiation Protection

ECD electron capture detector

ETEX European Tracer Experiment

GC gas chromatography

HPAC Hazard Prediction and Assessment Capability

i-PPCH perfluoroisopropylcyclohexane

JWA Japan Weather Association

MLOQ method level of quantitation

MSL mean sea level

PDCB perfluorodimethylcyclobutane

PDCH perfluoro-1,2-dimethylcyclohexane

$\mathrm{PECH} \quad$ perfluoroethylcyclohexane

PFT perfluorocarbon tracer

$\mathrm{PMCH} \quad$ perfluoromethylcyclohexane

PMCP perfluoromethylcyclopentane

PTCH perfluorotrimethylcyclohexane

TEAM Tracer Experiment and Atmospheric Modeling (project)

UTC coordinated universal time

WGS World Geographic System 



\section{Acknowledgements}

This research was supported by the U.S. Department of Energy (DOE) National Nuclear Security Administration NA-46 Office of International Emergency Management and Cooperation under Contract DE-AC05-76RL01830. Pacific Northwest National Laboratory (PNNL) is operated for DOE by Battelle.

The development of this experimental plan for the proposed Asian long-range tracer study was accomplished at the request of Vince McClelland (DOE NA-46) as suggested by Mike Bradley (Lawrence Livermore National Laboratory), the U.S. lead for the Tracer Experiment and Atmospheric Modeling (TEAM) Project. The TEAM partners are China, Japan, South Korea, and the United States.

We thank the following individuals for providing input in developing this proposed experimental plan: Rentai Yao (China Institute for Radiation Protection), Masamichi Chino (Japan Atomic Energy Agency), Hiromi Kojima (Japan Weather Agency), Moon-Hee Han (Korean Atomic Energy Research Institute), Tom Watson and John Heiser (Brookhaven National Laboratory), Frank Sornatale (Air Force Weather), and Kirk Clawson (NOAA Air Resources Laboratory). We also thank Stefano Galmarini (Joint Research Center of the European Commission), and Phil Vogt and Garrett Keating (Lawrence Livermore National Laboratory) for sharing information through their presentation at the Asian Tracer Experiment and Atmospheric Modeling Workshop held at Pleasanton, California on October 23-26, 2006.

We thank Jeremy Rishel of PNNL for providing modeling simulations and for analysis of the Asian meteorological data. We also thank Marty Leach and Mike Bradley of Lawrence Livermore National Laboratory for their insights, comments, and review of this experimental plan. 



\section{Table of Contents}

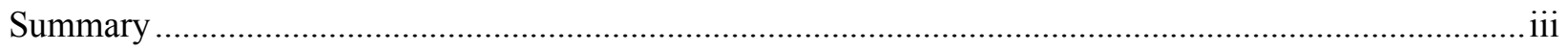

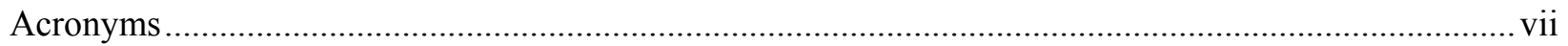

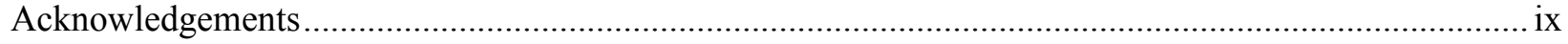

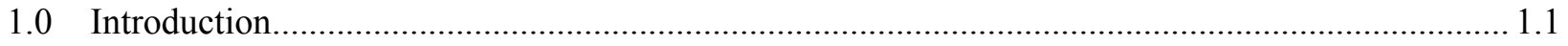

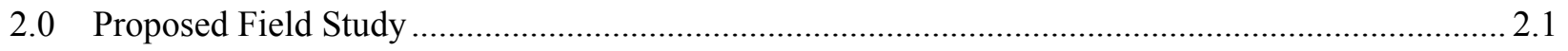

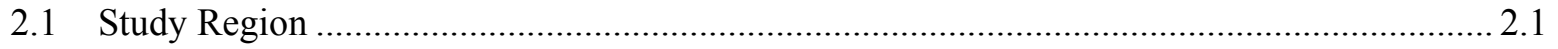

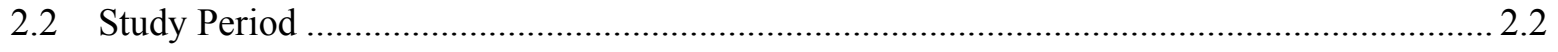

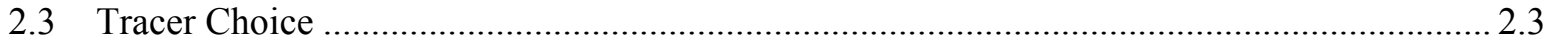

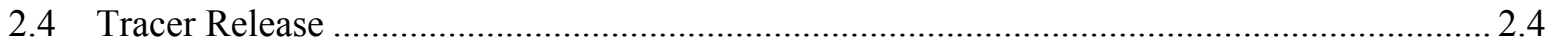

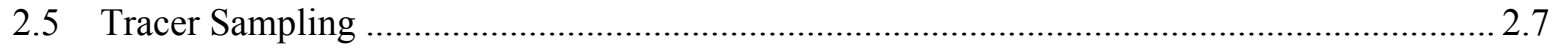

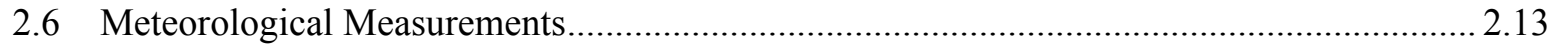

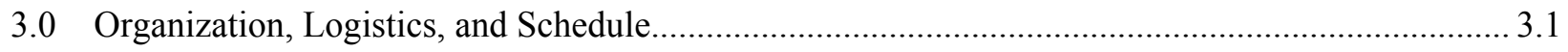

3.1 Organizational and Administrative Activities .................................................................. 3.1

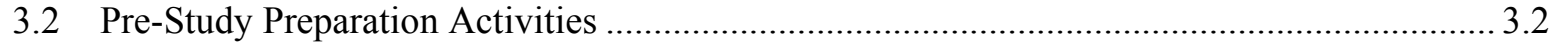

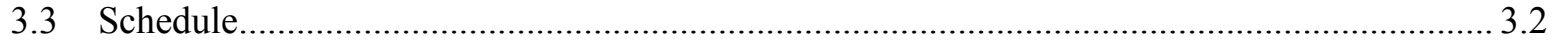

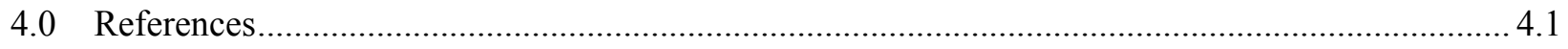

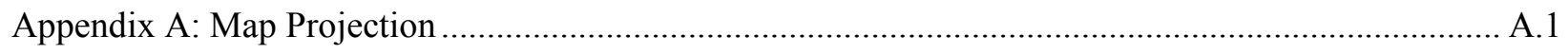

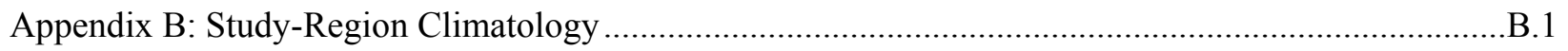

Appendix C: Tracer Measurements Near Background …....................................................................

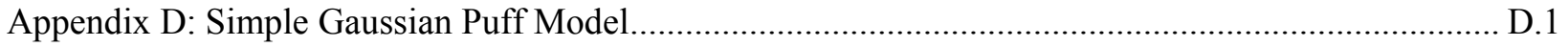

Appendix E: Winds from Central China to Central Japan ................................................................... 


\section{Figures}

2.1. Study Region with Latitude and Longitude Grids as well as Easting and Northing Coordinates from the Lambert Conformal Conic Projection Described in Appendix A ................................... 2.1

2.2. Probability of Releases from Yinchuan Reaching the Chinese Coast (Yantai), South Korea, and Central Japan for All Months .............................................................................................. 2.2

2.3. Proposed Locations of the 167 Tracer Samplers for the Asian Tracer Study ............................... 2.9

2.4. Proposed Locations of the Majority of the Tracer Samplers Located in China.............................. 2.9

2.5. Asian Tracer Study Domain Showing a Tracer Plume at Various Times Released from

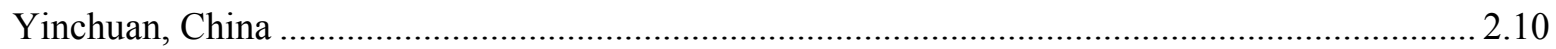

2.6. Results of the HPAC Simulation for a Release in Yinchuan ....................................................... 2.11

3.1. Proposed Schedule of Milestones and Tasks Necessary to Accomplish the Asian Long-Range

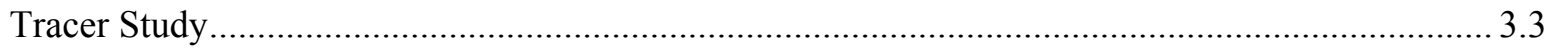

\section{Tables}

2.1. Acronyms, Chemical Names, Chemical Formulae, and Molecular Weights of PFTs Analyzed by BNL

2.2. Recommended Sampler Start Times, Sampling Duration, and Sample Integration Times for the Tracer Samplers at Various Distances Downwind from the Release. 


\subsection{Introduction}

An important factor for effective emergency response to an event involving harmful airborne materials is having validated atmospheric dispersion models that can track and forecast the path of airborne materials even as far as several thousand kilometers. A primary element of the Asian Tracer Experiment and Atmospheric Modeling (TEAM) Project is to design and conduct an Asian long-range tracer study to provide downwind concentration measurements for evaluating the applicability of atmospheric-dispersion models to eastern Asia.

The goal of any tracer study is to provide accurate (within 10\%) tracer measurements throughout the study domain. An equally important goal of a tracer study is to provide these concentrations at time and space intervals commensurate with the scientific objectives of the study. For example, a near-field $(\sim 10-\mathrm{km})$ tracer study would dictate fine-resolution tracer measurements (5- to 30-minute averaging times and 200- to 2000-meters sampler spacing), whereas a long-range ( 2000-km) tracer study would dictate coarse resolution tracer measurements (3- to 24-hour averaging times and 100- to 500-km sampler spacing).

For a large tracer study to be successful (i.e., deliver accurate tracer concentrations in a timely fashion), meticulous planning and experienced staff are critical. The design of a large tracer study is generally bounded by the funds available and the number of tracer sampling instruments and sample containers available for accomplishing the study. A successfully designed tracer study balances the equipment and staff available to accomplish the scientific goals of the study against the funds available and logistical constraints in conducting the study. For example, deploying over 150 tracer samplers over a 3000-km study domain will require many individuals and detailed planning.

Another important element of a successful tracer study is that appropriate and accurate meteorological measurements are made during the study to supplement measurements from the permanent meteorological networks in the study area. Dispersion models are typically evaluated using the tracer data from the field study and the meteorological data from the existing permanent meteorological network. However, the additional meteorological measurements during the study periods are important to determine whether the models may not be treating the physics of the boundary layer properly, or perhaps the permanent meteorological network needs to be enhanced.

This document proposes a design of an Asian long-range tracer study and lays out all the steps necessary to successfully conduct the study and provide accurate tracer and meteorological data within a reasonable period after the study. The proposed field design is provided as a vehicle for all the TEAM partners to come to an agreement as to the design and schedule such that responsibilities can be assigned, budgets allocated, and the many steps needed to plan for and conduct the field study can begin. 



\subsection{Proposed Field Study}

The tracer study proposed here is not intended to finalize the study design but rather to provide a vehicle for discussion among the TEAM partners (China, South Korea, Japan, and the United States) about the tracer-study design and to identify and discuss all the steps necessary to prepare for and conduct a field study of this size. We will be very specific in the design to show all the efforts and schedule needed to successfully accomplish an Asian long-range tracer study.

\subsection{Study Region}

The primary objective of this study is to gather tracer and meteorological data within an approximately $3000-\mathrm{km}$-long study region ranging from central China to Japan. The $5000-\mathrm{km}$ by 4000-km map shown in Figure 2.1 bounds the regions where the tracer and meteorological measurements will be made. The map is based on a Lambert Conformal Conic projection with the specifications of the projection given in Appendix A. We suggest that this projection and corresponding rectangular coordinate system shown in Figure 2.1 be the accepted projection for conveying any TEAM study georeferenced information. Additionally, we recommend, for consistency, that the geodetic coordinates (longitude, latitude) be based on the World Geographic System (WGS) 1984 datum.

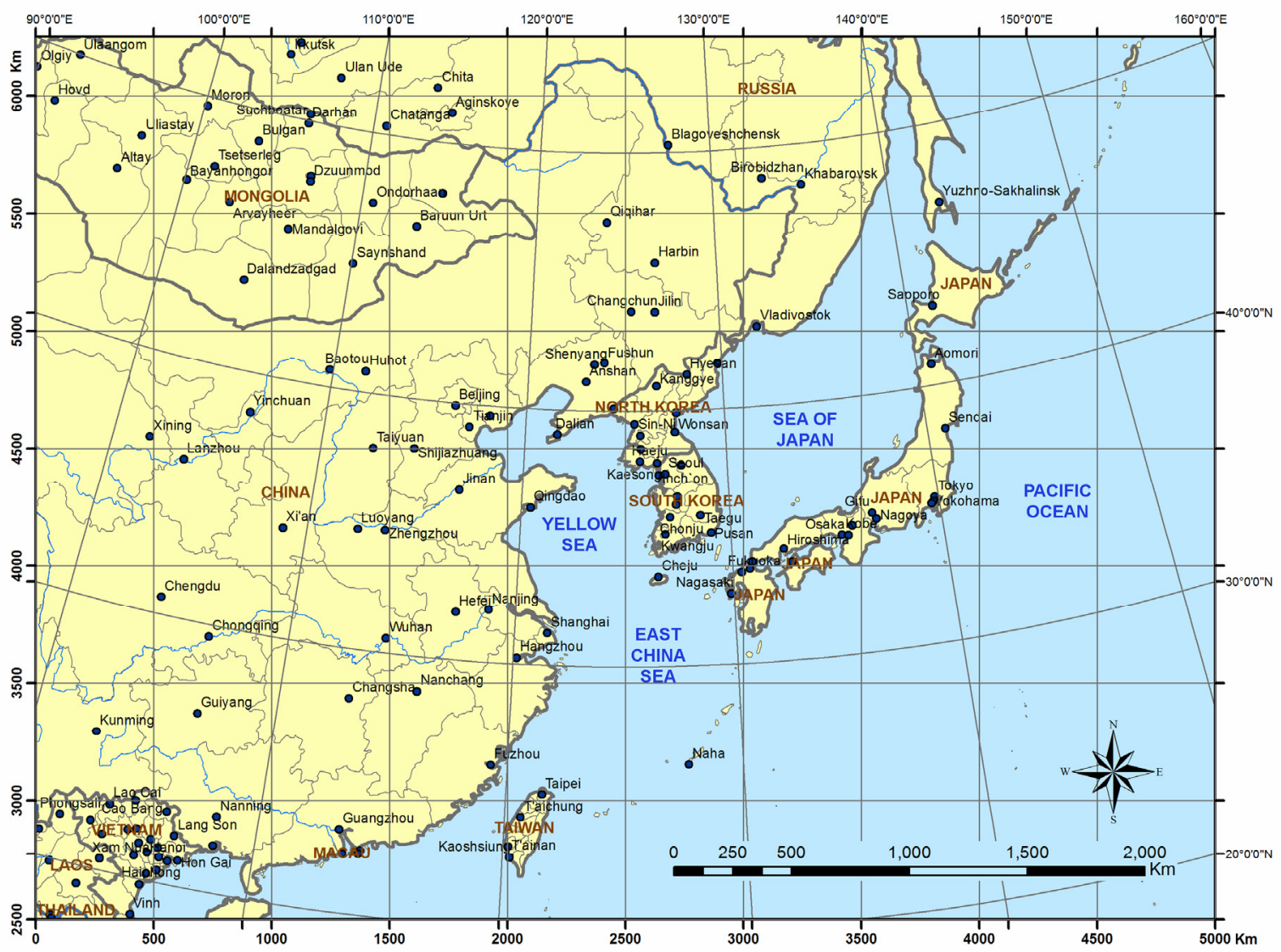

Figure 2.1. Study Region with Latitude and Longitude Grids as well as Easting and Northing Coordinates from the Lambert Conformal Conic Projection Described in Appendix A 


\subsection{Study Period}

Considerable meteorological analysis and dispersion estimates done by the TEAM partners points to March-April and November-December as the best months for having persistent westerly winds across eastern Asia such that tracer released in central China will move easterly over several days to coastal China, South Korea, and eventually to Japan. Summarized in Figure 2.2 are the trajectory analyses done by the China Institute for Radiation Protection (CIRP) for a release from Yinchuan. They computed trajectories for releases every 3 hours beginning at 00 coordinated universal time (UTC) for the 4-year period of 2001 through 2005. Shown in the figure are the percentages of trajectories that reached specific locations during each month of the year. The highest probably (10 to 30\%) of releases from Yinchuan reaching the Chinese coast (Yantai), South Korea, and central Japan occur during March-April and November-December.

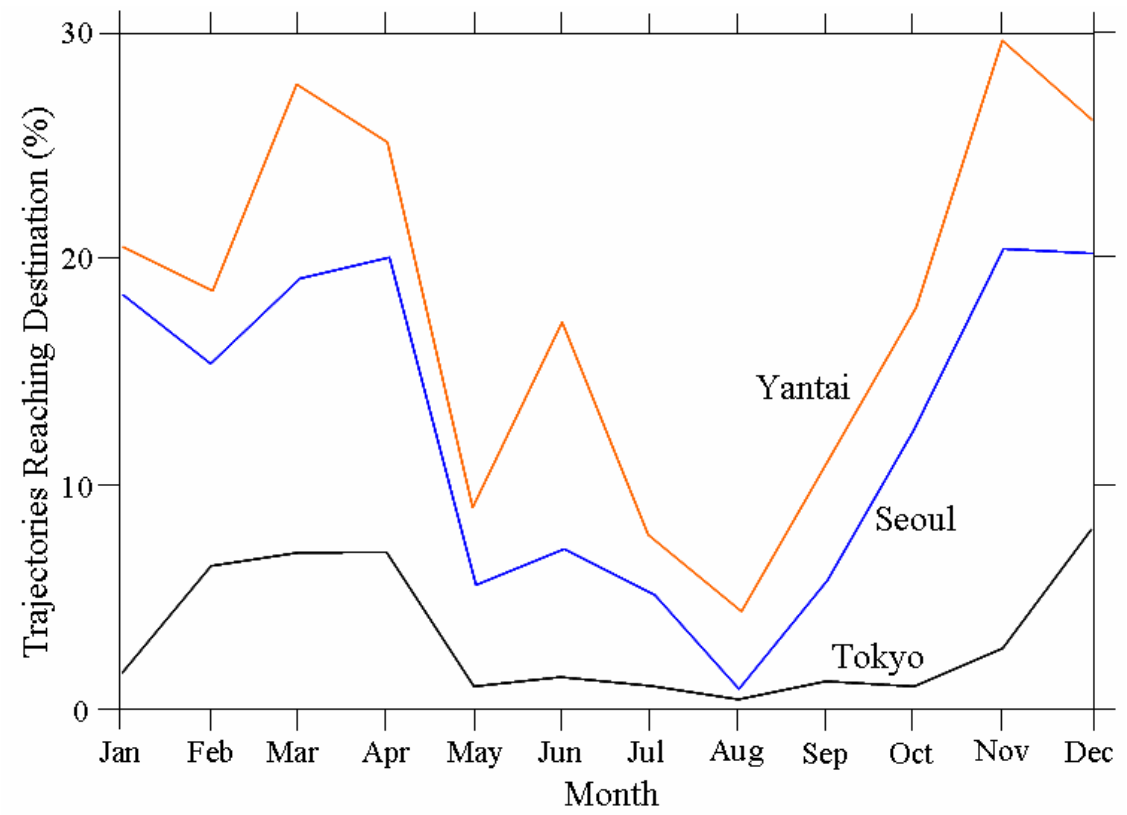

Figure 2.2. Probability of Releases from Yinchuan Reaching the Chinese Coast (Yantai), South Korea, and Central Japan for All Months. Values are from trajectory analyses given by Xuan Yiren of the CIRP.

The weather conditions expected during the study period are important to consider in deciding what time of year to conduct the field study. The March-April and November-December periods are premonsoonal and post-monsoonal periods, respectively, and are desirable periods with the least rainfall. However, the temperatures across the study region are much more favorable for conducting the field study during the March-April period (above freezing) than during the November-December period (below freezing in central to northern China) with April having the most favorable weather conditions. Appendix B gives the spring and fall climatology for 14 cities throughout the study region. The low temperatures in central to northern China can be $-10^{\circ} \mathrm{C}$ during November-December, making field logistics potentially more difficult and the failure of sampling instruments more likely because of potential battery failures in the cold temperatures. Perhaps the best time to conduct the Asian long-range tracer study is during April when winds are favorable for easterly transport from central China, and the climate is favorable for field operations. However, considerably more analysis must be accomplished to 
determine the likelihood of experimental periods with winds favorable for transport to as far as South Korea and Japan.

For discussion purposes, we will consider the field study period to begin on April 1, 2009, and continue for at most 4 weeks until two tracer releases and corresponding sampling have occurred. Field operations setup will begin during early-to-mid March 2009 such that all field components are ready for a first tracer release on April $1^{\text {st }}$ if the weather forecast is favorable. Spring 2009 is the earliest the tracer study can occur because of the lead time needed to prepare all equipment, purchase tracer, conduct background tracer studies, and conduct dry-runs with the meteorological forecast team and the sampler field-deployment teams. Each field-study component will be discussed more thoroughly later in this report.

\subsection{Tracer Choice}

The gaseous tracers of choice for long-range tracer experiments are PFTs that are safe, inert, and have very low global background levels (few parts tracer in $10^{15}$ parts of air by volume). Because of the low global background levels (1000 times less than sulfur hexafluoride, for example), tracer release rates needed for long-range dispersion studies are attainable with current release technology. Of course, of equal importance to the low background levels of PFTs are the well-established sampling and analytical methods for analyzing collected air samples to global background levels. The typical analytical method is based on gas chromatography using an electron capture detector (GC-ECD), and the necessary sampling method is to concentrate the sample onto an adsorbent within a small glass or metal tube during sample collection. By concentrating the sample, enough tracer mass can be accumulated from the ambient air to have a significant signal on the GC-ECD system, even for air at global background levels. The sampling and analysis methods will be discussed in more detail later in this report.

Because of the inherent complexity of a long-range tracer experiment in matching the sampler spacing and integration times with the released material moving through the sampling grid over multiple days, only two PFTs will be used during the study. The two PFTs used will be perfluoromethylcyclopentane (PMCP) and perfluoromethylcyclohexane (PMCH) because of their long history of use. The sampling and analytical methods are well established, and the three TEAM partners (China, Japan, and the United States) likely to collect and analyze the air samples have existing capabilities and/or expertise for sampling and analyzing for these two PFTs.

Another essential consideration in analyzing the collected air samples is that each partner laboratory be able to resolve other PFTs besides just PMCP and PMCH. For example, perfluoro-1,4dimethylcyclohexane (pt-PDCH) is often used to establish (or confirm) the actual volume of air sampled through an adsorbent tube. The method for calculating sample volume will be discussed later.

Additionally, the released tracers are never pure and may contain as much as $10 \%$ of other PFTs. This is not a major issue (unless pt-PDCH is a contaminant because of its use for sample volume correction) other than one analytical laboratory may have $10 \%$ more uncertainty in their reported PMCP or PMCH concentrations if one of the contaminant PFTs is not resolved from either of these two PFTs. Table 2.1 lists the seven PFTs that can be used as tracers by Brookhaven National Laboratory (BNL). Note that four isomers of PDCH are listed in the table and were resolved in their analysis. The TEAM Japanese group also resolved these four isomers of PDCH in their chemical analysis. 
Table 2.1. Acronyms, Chemical Names, Chemical Formulae, and Molecular Weights of PFTs Analyzed by BNL

\begin{tabular}{||l|l|c|c||}
\hline \hline \multicolumn{1}{|c|}{ Acronym } & \multicolumn{1}{c|}{ Chemical Name } & Formula & $\begin{array}{c}\text { Mol. Weight } \\
\text { (g mol }{ }^{-1} \text { ) }\end{array}$ \\
\hline \hline PDCB & Perfluorodimethylcyclobutane & $\mathrm{C}_{6} \mathrm{~F}_{12}$ & 300 \\
\hline PMCP & Perfluoromethylcyclopentane & $\mathrm{C}_{6} \mathrm{~F}_{12}$ & 300 \\
\hline PMCH & Perfluoromethylcyclohexane & $\mathrm{C}_{7} \mathrm{~F}_{14}$ & 350 \\
\hline oc-PDCH & Perfluoro-1,2-dimethylcyclohexane & $\mathrm{C}_{8} \mathrm{~F}_{16}$ & 400 \\
\hline pt-PDCH & Perfluoro-1,4-dimethylcyclohexane & $\mathrm{C}_{8} \mathrm{~F}_{16}$ & 400 \\
\hline mc-PDCH & Perfluoro-1,3-dimethylcyclohexane & $\mathrm{C}_{8} \mathrm{~F}_{16}$ & 400 \\
\hline mt-PDCH & Perfluoro-1,3-dimethylcyclohexane & $\mathrm{C}_{8} \mathrm{~F}_{16}$ & 400 \\
\hline PECH & Perfluoroethylcyclohexane & $\mathrm{C}_{8} \mathrm{~F}_{16}$ & 400 \\
\hline i-PPCH & Perfluoroisopropylcyclohexane & $\mathrm{C}_{9} \mathrm{~F}_{18}$ & 450 \\
\hline PTCH & Perfluorotrimethylcyclohexane & $\mathrm{C}_{9} \mathrm{~F}_{18}$ & 450 \\
\hline
\end{tabular}

As is discussed in the next section, a strategy of releasing one tracer right after the other may be employed if it is unlikely, because of weather, that two separate release and transport experiments can be realized during the April study period. Consequently, it will be essential that the PMCP tracer to be released does not contain any $\mathrm{PMCH}$ because of the later release of $\mathrm{PMCH}$, and the $\mathrm{PMCH}$ tracer to be released does not contain any PMCP because of the earlier release of PMCP. It will be important to work with the prospective PFT vendor(s) to be sure tracer interferences are not an issue. For now, we will assume that the two tracers for the Asian study are $\mathrm{PMCP}$ and $\mathrm{PMCH}$; however, these may change, depending on availability from vendors and the need to eliminate cross-contamination. As a note, a rough estimate of the cost of PMCH from F2 Chemicals Company is $\sim \$ 500 / \mathrm{kg}$ for an order of $1000 \mathrm{~kg}$ (from M. Chino at Oct. 2006 workshop).

\subsection{Tracer Release}

For discussion purposes, we will consider that two tracer experiments (release and sampling) will occur during the assumed April study period beginning on April 1, 2009. We will consider the tracer to be released from Yinchuan as proposed by CIRP. As will be described further below, each tracer experiment is expected to take 5 to 7 days (depending on the wind speeds) with at least 3 days in between the two tracer experiments for gathering of samplers, changing sampling tubes, and preparing for the next deployment. We propose that each tracer release begin at 00 UTC (8 AM local time) and last for 12 hours. A 12-hour-long tracer release will result in an approximately 250-km-long initial tracer plume (assuming $\sim 6 \mathrm{~m} \mathrm{~s}^{-1}$ winds) that will transport and diffuse across the study region. We believe that a 12-hlong release is sufficient for providing enough tracer to track across the study region, yet not too long such that possible variations in the local meteorology near the release site affect the character of the initial plume. A 12-h-long release beginning at 8 AM local time will avoid the possibility of local meteorological changes from daytime to nighttime conditions, which could significantly affect the character of the released plume in the vicinity of the release.

Having favorable transport wind conditions will dictate whether two 7-day-long tracer experiments (with 3 days in between) can be conducted within the April study period. In case winds are not favorable during the first part of April and it appears that only one release and subsequent sampling event can 
occur, then an alternate plan will be to conduct the two tracer releases (and sampling) within one 8-day period. That is, one release will occur at $00 \mathrm{UTC}$, and the second release will occur the next day at 00 UTC. This alternate plan, therefore, requires two different tracers (thus the decision to use PMCP and PMCH discussed above) so that the two 12-h-long releases can occur at 00 UTC on two consecutive days without being concerned about one release affecting the other.

As discussed in Appendix $\mathrm{C}$, the minimum PMCP and PMCH concentration that can be detected above global background levels ( $\sim 7 \mathrm{ppq}$ for both tracers) is $\sim 1$ part per quadrillion (ppq) by volume, which is 1 part tracer in $10^{15}$ parts air by volume. Attaining this level of plume detection assumes very accurate sampling/analysis capabilities as discussed in Appendix C.

A design element of the Asian tracer study is to detect the tracer plume in central Japan at $\sim 3000 \mathrm{~km}$ downwind from the release. A reasonable PMCP and $\mathrm{PMCH}$ concentration range for investigating the spatial structure of the plume at $3000 \mathrm{~km}$ would be from $1 \mathrm{ppq}$ to $20 \mathrm{ppq}$ or perhaps up to $50 \mathrm{ppq}$. For discussion purposes, let's assume we want a maximum tracer concentration in the plume at $3000 \mathrm{~km}$ to be 50 ppq. This design goal of $50 \mathrm{ppq}$ at the plume center over central Japan is an aggressive goal, but is worth considering because of the ability to obtain more definition of the characteristics (e.g., peak concentration and plume boundaries) of the tracer plume.

Estimating the appropriate amount of tracers to be released is extremely important because no matter how good the meteorological measurements, the tracer sampling capabilities, the tracer analytical capabilities, and the favorability of the weather conditions during the study, a study will fail to accomplish its objectives if not enough tracer is released, the tracer release equipment fails, or the tracer release team is inexperienced. We will discuss possible tracer-release equipment and tracer-release protocols later in this report.

Initial guidance on the amount of PMCP and $\mathrm{PMCH}$ to release for the proposed Asian tracer study can be determined from previous long-range transport studies. During the European Tracer Experiment (ETEX; Nodop et al. 1998) two 12-hour-long tracer releases of $28 \mathrm{~kg} \mathrm{~h}^{-1}$ (PMCP) and $41 \mathrm{~kg} \mathrm{~h}^{-1}$ (PMCH) were made. Their distant samplers were at $\sim 2000 \mathrm{~km}$ from the release and showed a few 3-hour-average values at a few sampling locations of 1 to $2 \mathrm{ppq}$ above background levels for both tracer releases. These concentration values are considerably below our design criteria at $3000 \mathrm{~km}$ of $50 \mathrm{ppq}$ at the plume center. However, their measured values at $2000 \mathrm{~km}$ were not necessarily at the plume center; the terrain between the release and the distant sampler points is very mountainous, and the meteorology during the sampling periods was complex.

During the Across North America Tracer Experiment (ANATEX; Draxler et al. 1991), numerous 3-hour-long PFT releases were made over a 3-month period from two locations in the United States (Glasgow, Montana, and St. Cloud, Minnesota). The tracer PTCH was released from Glasgow at $28 \mathrm{~kg} \mathrm{~h}^{-1}$, and oc-PDCH (note that this PDCH isomer is labeled as o-PDCH in the ANATEX literature) was released from St. Cloud at $16 \mathrm{~kg} \mathrm{~h}^{-1}$. The tracer release rate was greater from Glasgow than from St. Cloud because of the greater transport distances to the last sampling arc on the east coast from the Glasgow site. The maximum distance to the last sampling arc was $\sim 3000 \mathrm{~km}$ and $\sim 2000 \mathrm{~km}$ for releases from Glasgow and St. Cloud, respectively. Note that the background concentrations of oc-PDCH and PTCH measured during ANATEX were both approximately $0.4 \mathrm{ppq}$, nearly a factor of 10 lower than the PFTs used in ETEX and proposed for the Asian tracer study. Also, the 24-h-average PTCH 
concentrations (with background removed) at the $\sim 3000-\mathrm{km}$ samplers appeared to be on the order of a few tenths of a ppq. Because of the much lower background levels of PTCH versus either PMCP or $\mathrm{PMCH}$, the PMCP and PMCH release rates must be on the order of a factor of 10 higher to have the same measurement results. Consequently, a PMCP release rate of $\sim 180 \mathrm{~kg} \mathrm{~h}^{-1}$ (adjusted for molecular weight differences) for 3 hours would roughly give the same plume resolution at $3000 \mathrm{~km}$ as with PTCH during ANATEX.

Using the ETEX and ANATEX results discussed above leads to an estimate of PMCP and PMCH release rates for the Asian study of roughly 60 to $80 \mathrm{~kg} \mathrm{~h}^{-1}$ to get a detectable tracer plume at $3000 \mathrm{~km}$. The 60 to $80 \mathrm{~kg} \mathrm{~h}^{-1}$ is based on adjusting the ETEX 12-h-long release rate for impacts at $3000 \mathrm{~km}$ rather than $2000 \mathrm{~km}$ (increase by roughly a factor of two) and adjusting the 3-h-long ANATEX releases to 12-hour-long releases (decrease by roughly a factor of 3 ) because of along-wind dispersion effects in the case of ANATEX. However, recall that the "PMCP-equivalent" tracer concentrations measured at distant sampling points for both ETEX and ANATEX were a few ppq above background. These measured concentrations are roughly a factor of 10 below our design target of $50 \mathrm{ppq}$ above background at the plume center in central Japan. We, of course, cannot increase the proposed tracer release rate for the Asian study by a factor of 10 because of the prohibitive tracer cost (several million dollars) and unproven capabilities for releasing that amount. We are also not sure if the maximum plume concentrations were actually measured at the distant sampling points in either ETEX or ANATEX.

In summary, based on ETEX and ANATEX results, PMCP and PMCH release rates for the Asian study of $\sim 100 \mathrm{~kg} \mathrm{~h}^{-1}$ would potentially result in a concentration range of from $1 \mathrm{ppq}$ to $10 \mathrm{ppq}$ above background concentration at $\sim 3000 \mathrm{~km}$. The estimated cost for 24 hours of release (two 12-hour release periods) is $\sim \$ 1.2 \mathrm{M}$. Another option to pursue to potentially bring down the cost of the tracer and to improve the dynamic range of tracer measured at $3000 \mathrm{~km}$ is to switch to oc-PDCH and PTCH as were used during ANATEX. Releasing roughly $60 \mathrm{~kg} \mathrm{~h}^{-1}$ of oc-PDCH and PTCH (adjusted for molecular weight differences from PMCP) would potentially reduce the cost to $\sim \$ 0.7 \mathrm{M}$ and provide a concentration range above background of roughly from 0.1 to $5 \mathrm{ppq}$. This is a 5-fold increase in the measurement range over that of PMCP and PMCH. However, going to oc-PDCH and PTCH as the tracers for the Asian study would require careful consideration. $\mathrm{PTCH}$ is typically not measured by various groups, and the experience with releasing and analyzing PTCH is limited. Vendors for PTCH would need to be identified, and the purity of the PTCH would need to be verified by the partners in the tracer tests (not the vendors).

Another method of estimating the required tracer release rate for the Asian study is to use atmospheric dispersion models. Team partners have used trajectory and dispersion models to investigate downwind transport paths and concentrations and to identify optimal times of the year for getting easterly transport from central China to South Korea and then to Japan. We will not discuss here the results of the other groups' modeling, but rather, we will use a simple puff model to provide rough estimates of needed release rates to obtain $50 \mathrm{ppq}$ at $3000 \mathrm{~km}$ under various conditions. Using the puff model described in Appendix D, we estimated that a PMCH release rate of $\sim 60 \mathrm{~kg} \mathrm{~h}^{-1}$ would give $\sim 50$-ppq maximum concentration at $3000 \mathrm{~km}$ downwind for $20-\mathrm{km} \mathrm{h}^{-1}$ transport winds and a 2-km-deep mixing depth. The horizontal dispersion rate was assumed to be that determined by Heffter (1965) for long-range transport where the horizontal dispersion coefficient is proportional to the plume travel time to the desired downwind distance as discussed in Appendix D. If we consider the horizontal dispersion rate to be 1.5 times that of Heffter's because of potential additional plume meander in more complicated 
meteorology, a release rate of $\sim 120 \mathrm{~kg} \mathrm{~h}^{-1}$ would result in $\sim 50$-ppq maximum concentration at $3000 \mathrm{~km}$. From this simple dispersion analysis and from the ETEX and ANATEX analysis above, we suggest that the release rate of PMCP and PMCH not be less that $100 \mathrm{~kg} \mathrm{~h}^{-1}$. Of course, this recommended release rate should be further refined based on more detailed analysis of the model runs conducted by TEAM members using real meteorology.

As discussed previously, one tracer release and sampling period would be on the order of 7 days for $3000-\mathrm{km}$ transport distances. Two experiments would require a minimum of 17 to 20 days with 3 to 5 days in between the experiments for preparation. ${ }^{\text {(a) }}$ Appendix E gives time-series plots of surface and upper air wind direction and wind speed for five weather stations in China from central China to the coast, and for one station in Japan. Winds for the months of April and December 2003 are given. The wind direction plots in Appendix E show the likely probability that two 7-day periods of steady winds from the west will accommodate two separate 7-day-long tracer release and sampling experiments. The $850-\mathrm{mb}$ and $700-\mathrm{mb}$ wind direction plots show the persistence of westerly winds for a considerable portion of both months, especially at Taiyuan and extending east to central Japan. We recommend considering relocating the release site to Taiyuan. This will not only increase the probably of continued easterly transport of the released tracer but will also increase the maximum possible tracer concentrations measured over central Japan. Central Japan is $\sim 2500 \mathrm{~km}$ east of Taiyuan. A PMCP and PMCH release rate of $\sim 100 \mathrm{~kg} \mathrm{~h}^{-1}$ from Taiyuan would result in maximum tracer concentrations over central Japan approaching the desired design level of $50 \mathrm{ppq}$. Moving the release east by $500 \mathrm{~km}$ from Yinchuan to Taiyuan will decrease the number of samplers required and therefore the number of samples collected, thus reducing the total cost of the study.

The details of the release equipment will not be discussed in this document. However, there are two primary methods for releasing large quantities of PFT. The first is to volatilize the PFT on a hot plate and then vent it to the atmosphere with a diluent-airstream through a small stack. The second is to use a rapidly spinning atomizer that disperses fine-liquid PFT aerosols that immediately evaporate in the ambient air. It is not clear at this time which method is best. We know that the heated method of release was proved to be viable in ETEX, and a 12-h-long release could be maintained. The spinning atomizer method has also been demonstrated for long-duration (several hours) releases and has been dependable in previous applications. Further evaluation of which release method is better, and a decision will be made accordingly.

Well before going into the field, it is very important to have each analytical laboratory (Chinese, Japanese, and United States) analyze the tracers to be released for their PFT chemical composition. In this way, potential interfering perfluorocarbon compounds contained in the release material can be identified. Mitigating steps can then be taken if necessary.

\subsection{Tracer Sampling}

The most efficient sampler layout for capturing a plume from a single-point release is a polar grid. With a polar grid, the spatial resolution of the tracer samplers changes with the size of the plume. Near the source, the samplers are closer together to capture the crosswind structure of the narrow plume, and farther away from the source, the samplers become farther apart, commensurate with the laterally growing

(a) For details regarding lead times needed for making go/no-go decisions, see the second paragraph after Table 2.2 on page 2.12 . 
plume. Figure 2.3 and Figure 2.4 show the recommended sampler layout assuming the release at Yinchuan in central China. Figure 2.4 is simply a zoomed-in view of Figure 2.3, giving a better resolution of the samplers located in China and more detail on the major roads in the region. Note that the samplers are generally deployed every $5^{\circ}$ within a $90^{\circ}$ sector and on arcs spaced $250 \mathrm{~km}$ apart, beginning at $250 \mathrm{~km}$, from the release and extending to $3000 \mathrm{~km}$. Beyond the Chinese mainland over water, over South Korea, and over Japan, the sampling arcs deviate from being every $250 \mathrm{~km}$ to better accommodate the alignment of land.

These sampler locations, shown in Figure 2.3 and Figure 2.4, are ideally placed with no consideration for actual deployment issues of site access and sampler security. Actual sampler sites will need to be established by visiting the location of each potential site and identifying specific locations that meet the requirements of easy site access and security from tampering.

Figure 2.3 identifies 167 sampling locations as follows: 122 in China, 9 in the Yellow Sea, 9 in the South China Sea, 5 in South Korea, 18 in Japan, and 4 in the Sea of Japan. Those sampling locations over water are identified simply to give some recommended locations where buoy-borne, ship-borne, or airborne sampling may occur, provided these resources are available. Quality assurance considerations dictate the need for duplicate, control, and blank samplers. Consequently, the total number of PFT samplers needed for the Asian tracer study is $\sim 210$.

With potentially four different groups (China, Japan, South Korea, and the United States) collecting tracer samples (South Korea may use Japan's samplers and analytical capabilities), it will be important to have samplers from various organizations co-located at select sampling sites for quality assurance purposes. The samplers from the Japanese group will be located in Japan and may well be located in South Korea (depending on arrangements made by South Korea), and the samplers from China and the United States will be located in China. Whose samplers are used for over-water deployment will need further evaluation based on ease of operation and robustness of the units. We recommend a sampler deployment strategy within China to be the Chinese samplers located on the "5" radials and the U.S. samplers to be located on the " $10^{\circ}$ " radials. In this way, the Chinese and the United States provide backup for each other in case one or the other has fundamental difficulties with either their sampling or analytical equipment. Based on this sampler deployment in China, the Chinese would deploy 57 samplers (not including duplicates, controls, and blanks), and the United States would deploy 65 samplers (not including duplicates, controls, and blanks).

To show how the spatial coverage of the proposed tracer sampler layout can resolve a tracer plume released from Yinchuan, the Hazard Prediction and Assessment Capability (HPAC) puff model (Sykes et al. 2005) was run for a 12-h-long release in steady winds from the west at $18 \mathrm{~km} \mathrm{~h}^{-1}$. The release of $10 \mathrm{~kg} \mathrm{~h}^{-1}$ was begun at $00 \mathrm{UTC}$ ( 8 AM local time), and the model was executed assuming a daytime mixing layer of $2 \mathrm{~km}$ and a nighttime mixing later of $0.1 \mathrm{~km}$. Figure 2.5 shows 6 -h-average "snapshots" of the tracer plume as it moves across the study region. The tracer plume is first shown $12 \mathrm{~h}$ after the release started and then every $24 \mathrm{~h}$ up to $180 \mathrm{~h}$ (7.5 days) after the release start. This figure shows that the cross-wind structure of the tracer plume is well resolved with the recommended 5-degree separation of the radials and is reasonably well resolved in the along-wind direction. Note that the outermost contour of the tracer plume represents $1 \mathrm{ppq}$ for a $100-\mathrm{kg} \mathrm{h}^{-1}$ release $\left(0.1 \mathrm{ppq}\right.$ for $\left.10 \mathrm{~kg} \mathrm{~h}^{-1}\right)$. Also note that the plume centerline concentrations over central Japan are greater than $10 \mathrm{ppq}$ and may be as high as 20 to 30 ppq. This result also supports the recommendation of PMCP and PMCH release rates of $\sim 100 \mathrm{~kg} \mathrm{~h}^{-1}$. 


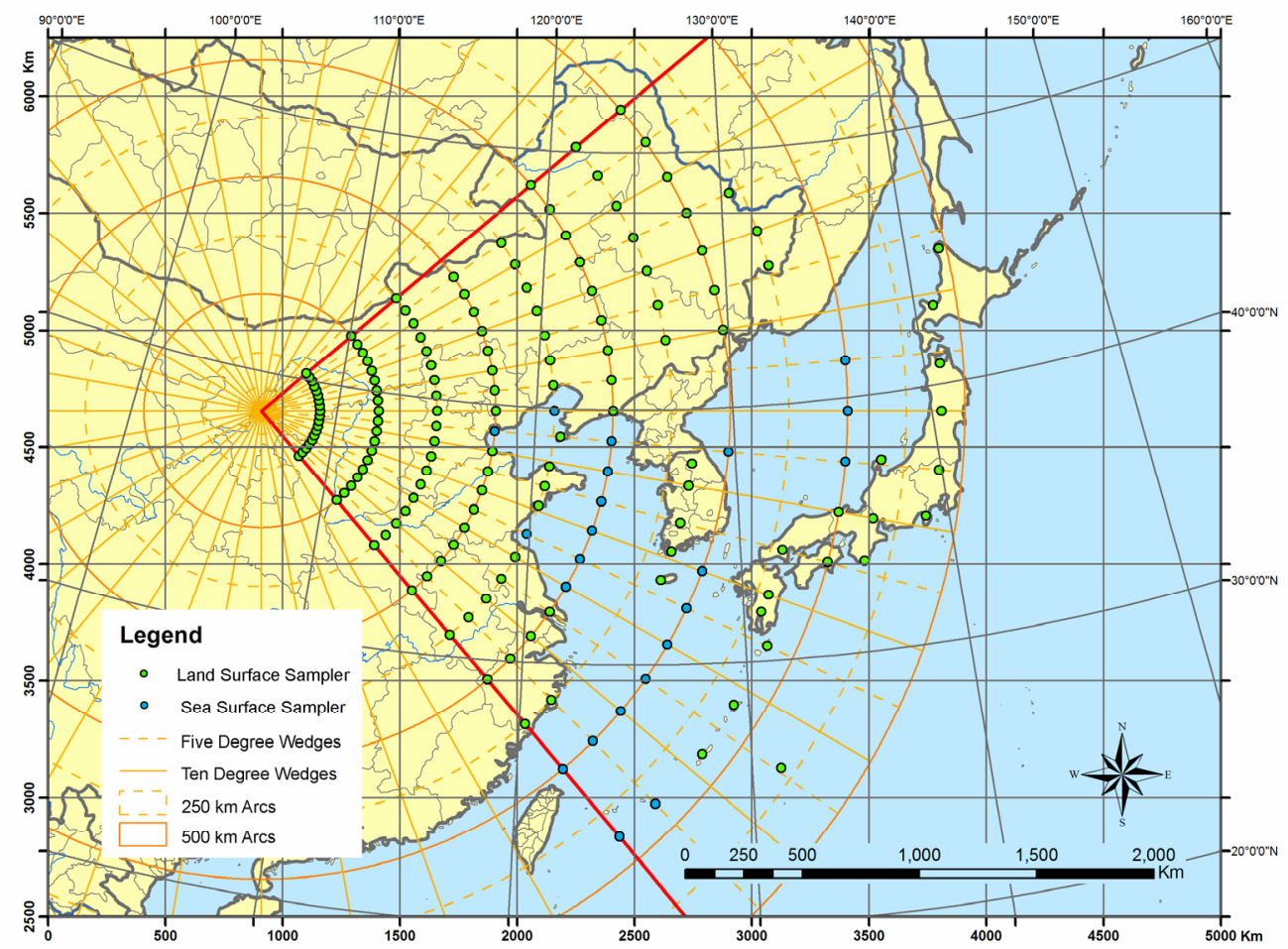

Figure 2.3. Proposed Locations of the 167 Tracer Samplers for the Asian Tracer Study. The radials are spaced every $5^{\circ}$ with every $10^{\circ}$ radial identified as a solid orange line. The arcs are spaced at $250 \mathrm{~km}$ with every $500-\mathrm{km}$ arc identified as a solid orange line.

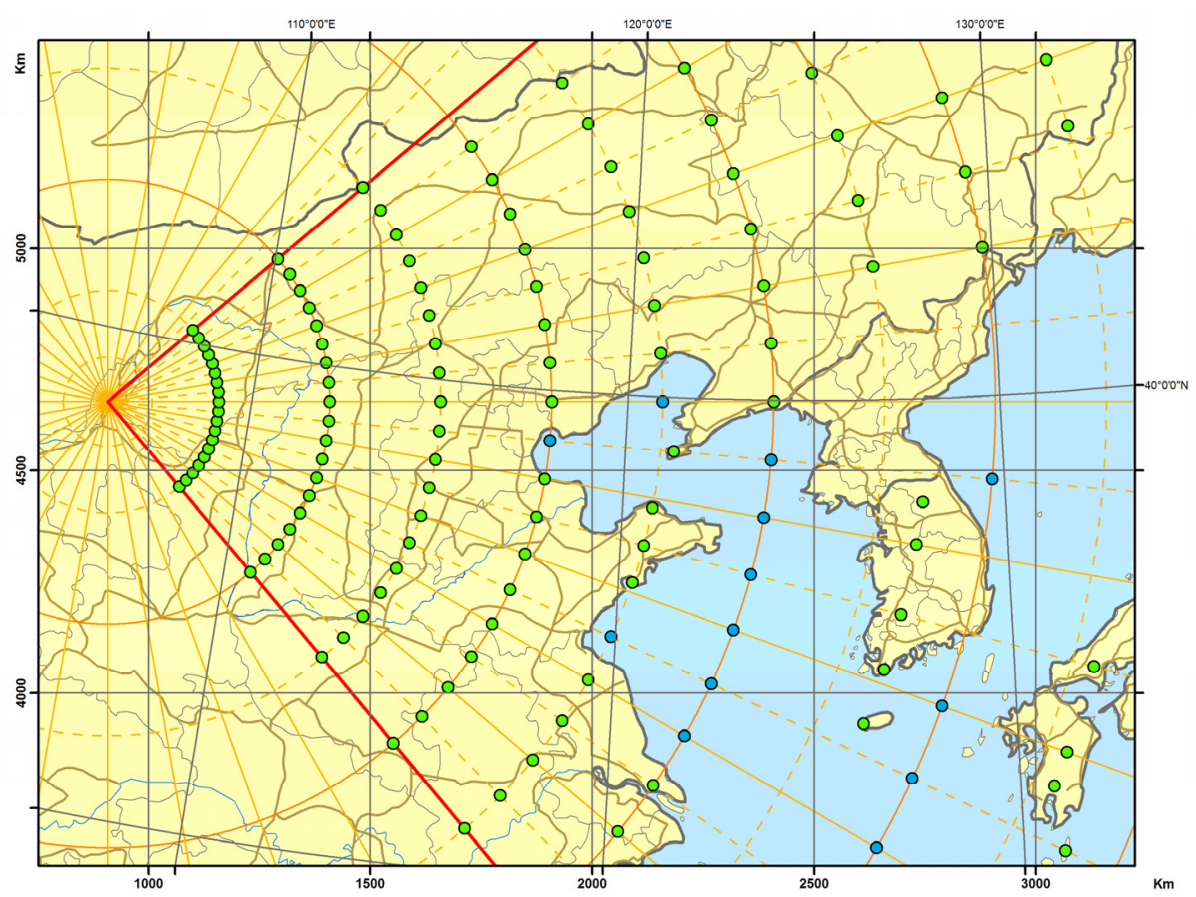

Figure 2.4. Proposed Locations of the Majority of the Tracer Samplers Located in China. This figure is a zoomed-in portion of the map given in Figure 2.3. 


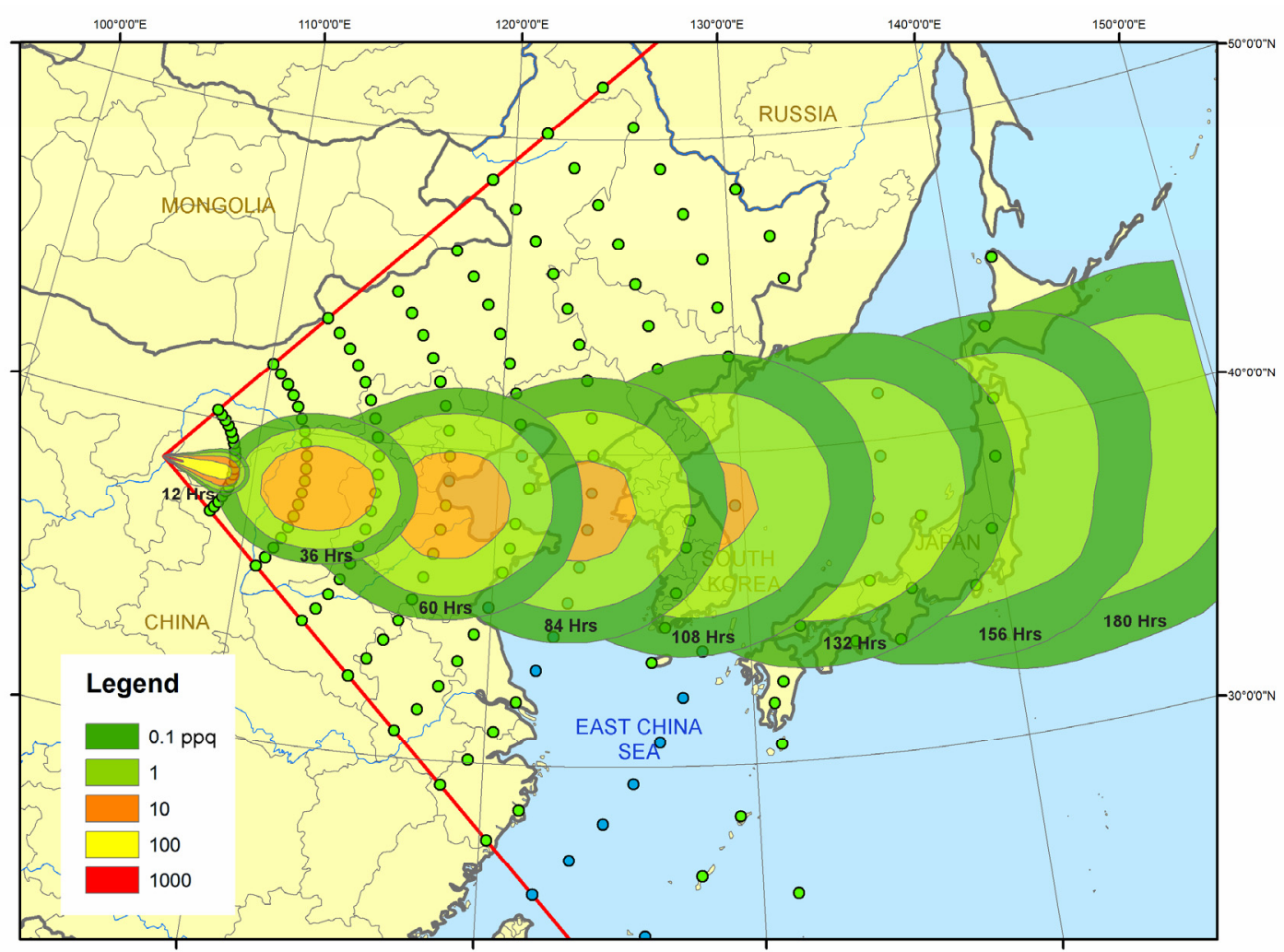

Figure 2.5. Asian Tracer Study Domain Showing a Tracer Plume at Various Times Released from Yinchuan, China. The tracer plume is a simulation from the HPAC puff dispersion model.

An important component of tracer sampler deployment is to determine appropriate sampler start and stop times, the individual sample integration times, and therefore, the number of sampling adsorbent tubes needed for each sampler. The information needed to determine the sampling times is an estimate of when the tracer reaches a sampler and how long it takes for the tracer plume to move across the sampling location. An estimate of the plume arrival time and plume transit time at sampler locations was determined from the HPAC simulation described above. Figure 2.6 gives time series plots of 3-h-average ground-level tracer concentrations at various downwind distances from the HPAC simulation. For example, the plume arrives at the 750-km sampling arc at $30 \mathrm{~h}$ after the release start and departs the arc at $72 \mathrm{~h}$ after the release start. The plume transit time at $750 \mathrm{~km}$ is $\sim 42 \mathrm{~h}$, indicating that a $6-\mathrm{h}$ sample integration time is reasonable at this distance, giving seven time points representing the tracer plume. Even at the $250 \mathrm{~km}$ sampling arc, a 6-h sample integration time is reasonable. 

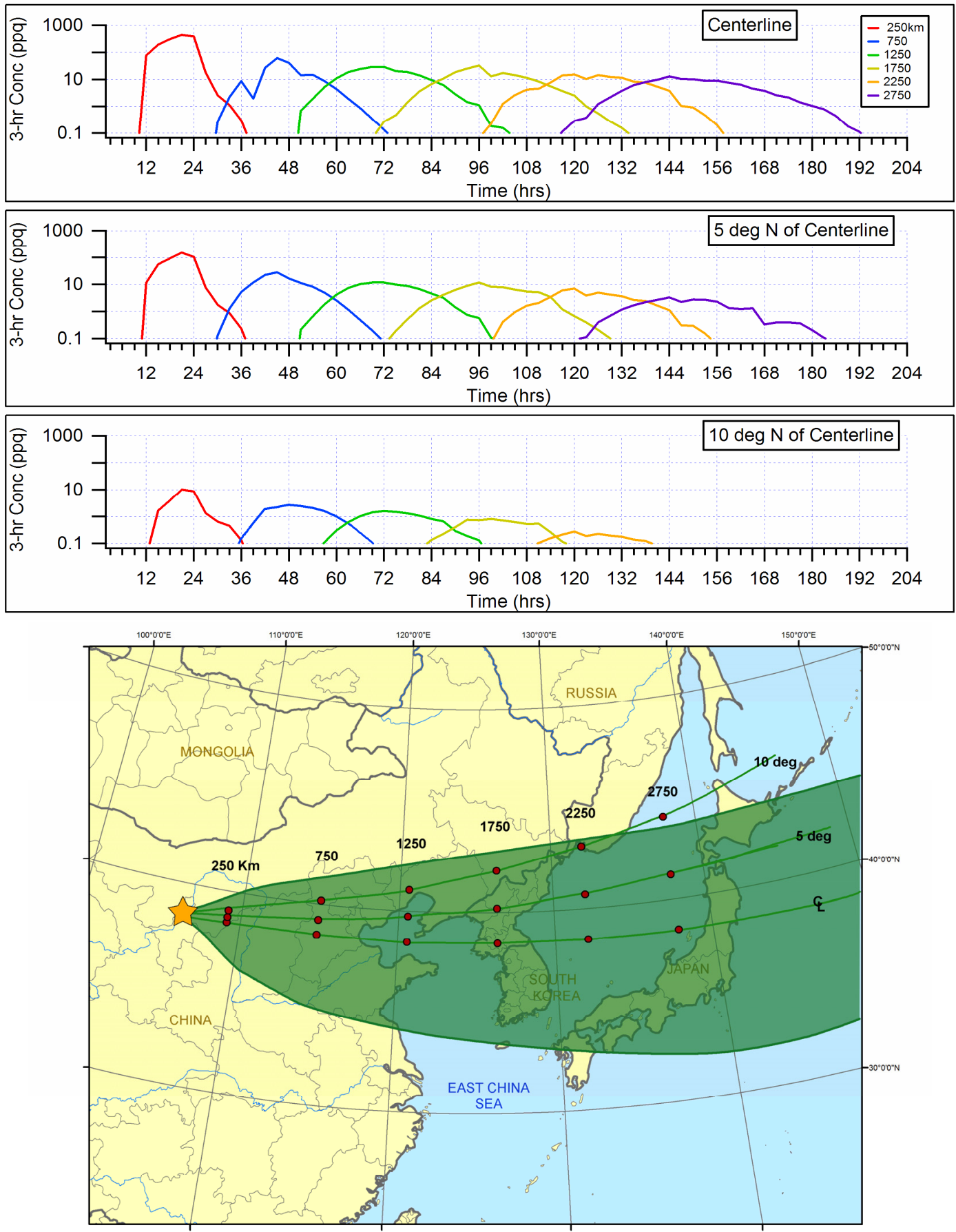

Figure 2.6. Results of the HPAC Simulation for a Release in Yinchuan. The top panel gives time series plots of tracer concentration at various downwind distances for a $10-\mathrm{kg} \mathrm{h}^{-1}$ release, and the bottom panel shows the plume envelope bounded by the 0.1-ppq limit (1-ppq limit for a 100$\mathrm{kg} \mathrm{h}^{-1}$ release). The red dots in the bottom panel show the locations of the concentrations given in the top panel. 
Based on an analysis of the information given in Figure 2.6, Table 2.2 gives recommended sampler start times as well as sampling duration and sample integration times at various distances from the release located in Yinchuan. These recommended values are a starting point for further refinement and revisions as the experimental planning proceeds. The estimated number of samples collected per tracer release is $\sim 2300$, not including duplicates, blanks, and controls. This number counts samples from all over-water samplers even though it is unlikely that this number of over-water samplers will be possible because of increased costs and complexities for deployment. A reasonable upper bound on the total number of tracer samples collected during the Asian tracer experiment is $\sim 6000$, including all quality assurance samples.

Table 2.2. Recommended Sampler Start Times, Sampling Duration, and Sample Integration Times for the Tracer Samplers at Various Distances Downwind from the Release

\begin{tabular}{|c|c|c|c|c|c||}
\hline $\begin{array}{c}\text { Sampling } \\
\text { Arc }\end{array}$ & $\begin{array}{c}\text { Start Time } \\
\text { (h after } \\
\text { release start) }\end{array}$ & $\begin{array}{c}\text { Sampling } \\
\text { Duration } \\
\text { (h) }\end{array}$ & $\begin{array}{c}\text { Integration } \\
\text { Time } \\
\text { (h) }\end{array}$ & $\begin{array}{c}\text { Number } \\
\text { Samples } \\
\text { Per Sampler }\end{array}$ & $\begin{array}{c}\text { Number } \\
\text { Samplers } \\
\text { On Arcs }\end{array}$ \\
\hline \hline $250-1000$ & 0 & 96 & 6 & 16 & 75 \\
\hline $1250-2000$ & 36 & 132 & 12 & 11 & 66 \\
\hline $2250-3000$ & 72 & 180 & 12 & 15 & 26 \\
\hline
\end{tabular}

A successful study requires diligence in documenting the sample chain of custody, following sample handling procedures, understanding the programming and setup procedures for each sampler, and documenting all the operating parameters for each sampler at deployment and at retrieval.

After review of the weather forecast by the field management team and the subsequent "go" by the field director, each of the four field sampling leads (China, Japan, South Korea, and United States) will initiate the programming and deployment of their respective samplers to their pre-determined sampler locations. Each sampling team lead will have several deployment centers (perhaps up to 10) with a sampling expert at each center to program the samplers, document the samples in each sampler, and record all of the pertinent information. The center lead will hand off the samplers to the individuals actually deploying the samplers. The deployment teams will then deliver the samplers to the designated sampling locations. It may be possible that all the first-deployed samplers ( 75 samplers) can be put in place within $24 \mathrm{~h}$ of a "go" decision and $12 \mathrm{~h}$ before the release start. A "go/no-go" decision would need to be made at least $36 \mathrm{~h}$ before the prospective release start time. This means that go/no-go decisions would need to be made by $8 \mathrm{PM}$ local time $36 \mathrm{~h}$ before the release start at $8 \mathrm{AM}$ local time. An evening go decision would allow for some of the samplers to be programmed that evening for early morning deployment to the most distant locations from the deployment center. The samplers closer to the deployment centers can be programmed and deployed during that next day, which is the day before the scheduled release. After deploying the near-field samplers, the appropriate deployment centers can prepare the next wave of samplers for deployment and have them in place at least $6 \mathrm{~h}$ before they are scheduled to start sampling.

We suggest that the Chinese and U.S. sampling teams locate at common deployment centers since most of the Chinese and U.S. samplers are intermixed geographically. In this way, common deployment teams may be able to be used, depending on the sampler delivery routes determined for each deployment team. Additionally, the sampling experts would be able to help each other if the need arises.

If some buoy-borne, ship-borne, and airborne sampling is planned for the Asian tracer study, then it would be best to designate an individual responsible for all these sampling activities. It would be the 
responsibility of this individual to direct the operations of the special sampler deployment centers. Coordinating the special sampling efforts will be complicated and will require considerable planning to be successful. We expect that if special over-water sampling is undertaken, the detailed planning will then evolve as the deployment resources (e.g., ships and airplanes) are identified and the extent of the sampling efforts are refined based on the available resources.

Another very important consideration in effective tracer sampling is to avoid any possibility that the samplers or sampling tubes will be contaminated. The most likely condition for sampler contamination is the samplers coming in the near proximity of anything to do with the tracer release operations, including the people who are conducting the release. This issue has been the downfall of several tracer experiments over the years.

The method of avoiding sample contamination is to be meticulous in planning that the release equipment, the tracer, and the people responsible for the release do not ever cross paths with the samples, sampling equipment, and sampling staff. The release equipment and tracer must be shipped separately from the sampling equipment both to and from the study area. Also, during field operations, the tracerrelease equipment, tracer, and team must be kept well away from any samplers, sampling tubes, and people responsible for sampling at all times.

Post-experiment analysis of the samples by each TEAM laboratory must be coordinated and a common set of data quality assurance protocols agreed to. For example, known and blind standards should be exchanged and analyzed for inter-comparison of the various laboratories. Because PFT sampling requires the volume of air sampled to be measured and/or calculated accurately, it is imperative that all laboratories agree on the best volume-correction method to apply. Perhaps the "tracer-ratio" method recommended by BNL is the best choice.

A survey of sampling equipment currently available from the TEAM partners reveals the need for a significant investment in new sampling equipment in order to be in a position to conduct the Asian longrange tracer study. The U.S. sampling and tracer analysis capabilities need upgrading to accomplish a study as demanding as the proposed Asian study. The primary U.S. group with the expertise for conducting a long-range PFT study is BNL, and they will need 110 new samplers (they already have a prototype that is being tested) and one new analytical system. The Chinese TEAM partners also need at least 100 new samplers and perhaps two new analytical systems. The Japanese TEAM partners are proposing to use the Japan Weather Association (JWA) samplers for sampling in Japan, and the South Koreans are initially proposing to use the JWA samplers in South Korea. JWA has existing analytical capabilities that will be used to analyze the samples collected in Japan and South Korea.

\subsection{Meteorological Measurements}

Another important element of a successful tracer study is that appropriate and accurate meteorological measurements be made during the study to supplement measurements from the permanent meteorological networks in the study area. Generally, equipment in permanent meteorological networks may not have the precision, threshold, or sampling frequency needed to characterize the dispersion meteorology of the atmospheric boundary layer, so it is useful to supplement the meteorological measurements with researchgrade instruments or increase the sampling frequency of certain instruments in the permanent network. For example, many rawinsonde observations are twice daily (00 and 12 UTC), so increasing the frequency during field study periods is sometimes very beneficial to better define the temporal evolution 
of the boundary layer. Additionally, it is very important to properly characterize the vertical structure (e.g., winds and temperature) of the boundary layer in the vicinity of the release, so instrumenting the release site with a surface tower, an acoustic sodar, a radar wind profiler, and a radiosonde system provides the needed information.

The evaluation of dispersion models should typically be made using the tracer data from the field study and the meteorological data from the existing permanent meteorological network and not use the meteorological measurements from the instruments deployed during the study period. However, the additional meteorological measurements during the study periods are important to determine whether the models may not be treating the physics of the boundary layer properly, or perhaps the permanent meteorological network needs to be enhanced. Evaluating the models against the measured tracer data with and without the enhanced meteorological measurements would help evaluate the fidelity of the models and the adequacy of the permanent meteorological network.

As the planning for the Asian tracer study progresses, additional meteorological measurements needed to interpret the tracer results will be determined, and the appropriate equipment will be arranged for field deployment. We recommend that a meteorological-field-team lead be assigned. This individual will lead the planning the measurements needed and coordinate all meteorological field operations, including overseeing the archiving of all the pertinent meteorological information. 


\subsection{Organization, Logistics, and Schedule}

Many important organizational and logistical elements of the Asian tracer study will need to be developed as the planning for the study progresses. Additionally, pre-field operation, field operation, and post-field operation efforts will need to be identified, responsibilities assigned, and planning completed.

A reasonable schedule for a successful Asian long-range tracer study is to conduct the study beginning on April 1, 2009, with field set-up and meteorological forecasting efforts beginning by midMarch 2009. Conducting the tracer study during April 2009 would allow for all the needed equipment to be fabricated and fully tested, the PFT tracer to be ordered, received, and validated for purity, and for preliminary field exercises to be conducted for testing the forecast team and for establishing background air concentrations. Another time-consuming effort that must be accomplished well before the planned April 2009 field study is to identify all the sampling locations. Every desired sampling location must be visited and a specific sampler position identified. With the small battery-powered samplers, often the easiest and most secure locations are to suspend the samplers from pre-installed hangers on existing poles. Installing the samplers at least 3 meters above the surface keeps them out of the reach of the local public.

The first critical step in accomplishing the Asian tracer study is the decision to go forward and the allocation of funding and engaging investigators. This should be done no later than October-November 2007 so long-lead-time activities can begin and preliminary spring 2008 field activities can be conducted. The important activities to be conducted beginning mid-March 2008 and continuing through to the end of April 2008 are to conduct background PFT measurements throughout the study region and to exercise the meteorological forecast team and evaluate their performance in predicting desirable release and sampling periods. The field director and field management team should also be in place before spring 2008 since the ultimate "go/no-go" decision is made by the field director with input from the field management team. The performance of the field management team with the critical input from the meteorological forecast team will be evaluated based on results of the spring 2008 preliminary exercise where the April 1 through 31,2008 , period will be treated as the "real study period" where two tracer release and sampling efforts (5 to 7 days each) must be conducted.

The primary long-lead time efforts needed to accomplish the Asian tracer study are 1) fabricate and test the $\sim 210$ new tracer samplers, 2) order, receive, and verify the purity of the two PFTs to be released, 3) procure, test, and verify the new GC-ECD analytical systems, and 4) establish specific locations of tracer samplers and deployment methods, especially for over-water samplers. The following sections summarize important elements that must be addressed to conduct a successful tracer study.

\subsection{Organizational and Administrative Activities}

- Partners agree to proceed so budgets can be allocated, responsibilities assigned and work begin as soon as possible.

- Establish field management team consisting of a field director and the following team leads who will then organize their respective team members:

- Meteorological forecast team

- Dispersion modeling team

- Tracer release team

- Meteorological measurements team 
- Tracer sampling team (five deputy leads - one from each partner with sampling and analytical capabilities and one to handle the special sampling [e.g., airborne])

- Data quality assurance and archive team.

- Develop field command center structure and communication procedures.

\subsection{Pre-Study Preparation Activities}

- Build and test new samplers and analytical equipment.

- Procure and test new GC-ECD analytical systems.

- Order tracers and verify purity of two tracers to be released.

- Conduct background tracer studies during the March to April 2008 preliminary study period.

- During the March to April 2008 preliminary study period, test the operation of the command center, determine the effectiveness of communication channels, and determine the accuracy of the go/no-go decisions based on the complete operations of the meteorological forecast and atmospheric modeling teams.

- Perform analytical laboratories inter-comparison studies.

- Conduct tracer sampling activities including:

- Locate and document all the tracer sampling sites throughout the study region

- Determine sampler deployment centers as well as deployment routes and schedules

- Perform sampler inter-comparison studies using standards and blanks

- Develop detailed field-sampling procedures and sample-custody protocols.

- Develop detailed quality assurance procedures and protocols.

- Develop tracer-release procedures.

\subsection{Schedule}

Figure 3.1 proposes a schedule with the activities necessary to accomplish a successful Asian tracer study and provides accurate tracer concentration data for model-validation exercises. 


\begin{tabular}{|c|c|c|c|c|c|c|c|c|c|c|c|}
\hline \multirow[b]{2}{*}{ Tasks \& Milestones } & 2007 & \multicolumn{4}{|c|}{$\begin{array}{r}2008 \\
\end{array}$} & \multicolumn{4}{|c|}{2009} & \multicolumn{2}{|c|}{2010} \\
\hline & \begin{tabular}{|l|l|} 
J-A-S & O-N-D \\
\end{tabular} & J-F-M & A-M-J & $\mathbf{J}-\mathbf{A}-\mathbf{S}$ & O-N-D & J-F-M & A-M-J & J-A-S & O-N-D & J-F-M & A-M-J \\
\hline 1. Commit To Proceed & & & & & & & & & & & \\
\hline 2. Allocate Budgets & $\underset{ }{2}$ & & & & $\mathbf{E}$ & & & & $\mathbf{E}$ & & \\
\hline 3. Fabricate and Test New Samplers & & & & & & $\mathbf{P}$ & & & & & \\
\hline 4. Procure, Install and Test Analytical Systems & & & & & $\mathbf{m}$ & & & & & & \\
\hline $\begin{array}{l}\text { 5. Complete Subset of New Samplers for } \\
\text { Background Study and Identify Field Sites }\end{array}$ & & & & & & & & & & & \\
\hline 6. Conduct Spring 2008 Preliminary Study & & & & & & & & & & & \\
\hline $\begin{array}{l}\text { 7. Determine Sites for Samplers \& Establish } \\
\text { Deployment and Sampling Procedures }\end{array}$ & & & & & & & & & & & \\
\hline 8. Procure Tracer and Establish Purity & & & & & $\mathbf{P}$ & & & & & & \\
\hline $\begin{array}{l}\text { 9. Conduct Inter-Laboratory Comparisons of } \\
\text { Samplers and Analytical Systems }\end{array}$ & & & & & & & & & & & \\
\hline 10. Finalize Experimental Plan & & & & & 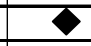 & & & & & & \\
\hline 11. Ship and Receive Equipment in Field & & & & & & & & & & & \\
\hline $\begin{array}{l}\text { 12. Conduct Field Study Including Set-Up and } \\
\text { Take-Down }\end{array}$ & & & & & & & & & & & \\
\hline 13. Ship Euipment and Samples from Field & & & & & & & & & & & \\
\hline 14. Chemical Analysis of Samples & & & & & & & & & & & \\
\hline $\begin{array}{l}\text { 15. Quality Assure, Document and Complete } \\
\text { Data Archive }\end{array}$ & & & & & & & & & & & \\
\hline 16. Final Data Archive with Documentation & & & & & & & & & & & \\
\hline ask Milestone & & & & & & & & & & & \\
\hline
\end{tabular}

Figure 3.1. Proposed Schedule of Milestones and Tasks Necessary to Accomplish the Asian LongRange Tracer Study 



\subsection{References}

Draxler, RR, R Dietz, RJ Lagomarsino and G Start. 1991. "Across North America tracer experiment (ANATEX): Sampling and analysis.” Atmospheric Environment. 12:2815-2836.

Heffter, JL. 1965. "The variation of horizontal diffusion parameters with time for travel periods of one hour or longer." J. Appl. Meteor. 4:153-156.

Kim, H, SK Yea, C Ro, CB Lee, M Jang, G Lee, E Yoo, and J Han. 2002. "Determination of atmospheric perfluorocarbon background concentrations of fL/L range at the western coastal area of Korea." Bull. Korean Chem. Soc. 23:301-308.

Nodop, K, R Connolly and F Girardi. 1998. "The field campaigns of the European tracer experiment (ETEX): Overview and results." Atmospheric Environment. 32:4095-4108.

Sykes, RI, SF Parker and DS Henn. 2005. SCIPUFF Version 2.1 Technical Documentation. Titan/ARAP Report No. 728. 

Appendix A

\section{Map Projection}





\section{Appendix A: Map Projection}

Given the extent and position of the Asian TEAM study area as shown in Figure 2.1 in the main body of this report, we have chosen a Lambert Conformal Conic projection with the parameters specified in Table A.1 as the best projection for reporting and visualizing geo-referenced information in a rectangular coordinate system. The central meridian of the projections was selected to be at the approximate midpoint of the study area between central China (Yinchuan) and Japan (Tokyo). We have set the false easting of the coordinate system to be $2500 \mathrm{~km}$ west of the central meridian, such that all the coordinates in the Asian TEAM coordinate system are positive. Note that the origin of the northing coordinate is the equator. Figure A.1 gives a pictorial representation of the positioning of the cone on the globe and shows the origin of the coordinate system. We suggest that all instrument-position coordinates be given in geodetic (longitude, latitude) and the Asian TEAM Project (ATP) coordinate system in easting and northing. If the study region changes as the planning for the Asian long-range tracer study progresses, then it may be appropriate to change the parameters of the Lambert Conformal Conic projects to more accurately represent the revised study area.

Table A.1. Lambert Conformal Conic Projection Parameters for the ATP

\begin{tabular}{||l|c||}
\hline \multicolumn{1}{|c|}{ PARAMETER } & VALUE \\
\hline Standard Parallel 1 & $27 \mathrm{deg} \mathrm{N}$ \\
\hline Standard Parallel 2 & $50 \mathrm{deg} \mathrm{N}$ \\
\hline Central Meridian & $125 \mathrm{deg} \mathrm{E}$ \\
\hline False Easting & $2500 \mathrm{~km}$ \\
\hline False Northing & $0 \mathrm{~km}$ \\
\hline Reference Ellipsoid & WGS 1984 \\
\hline
\end{tabular}




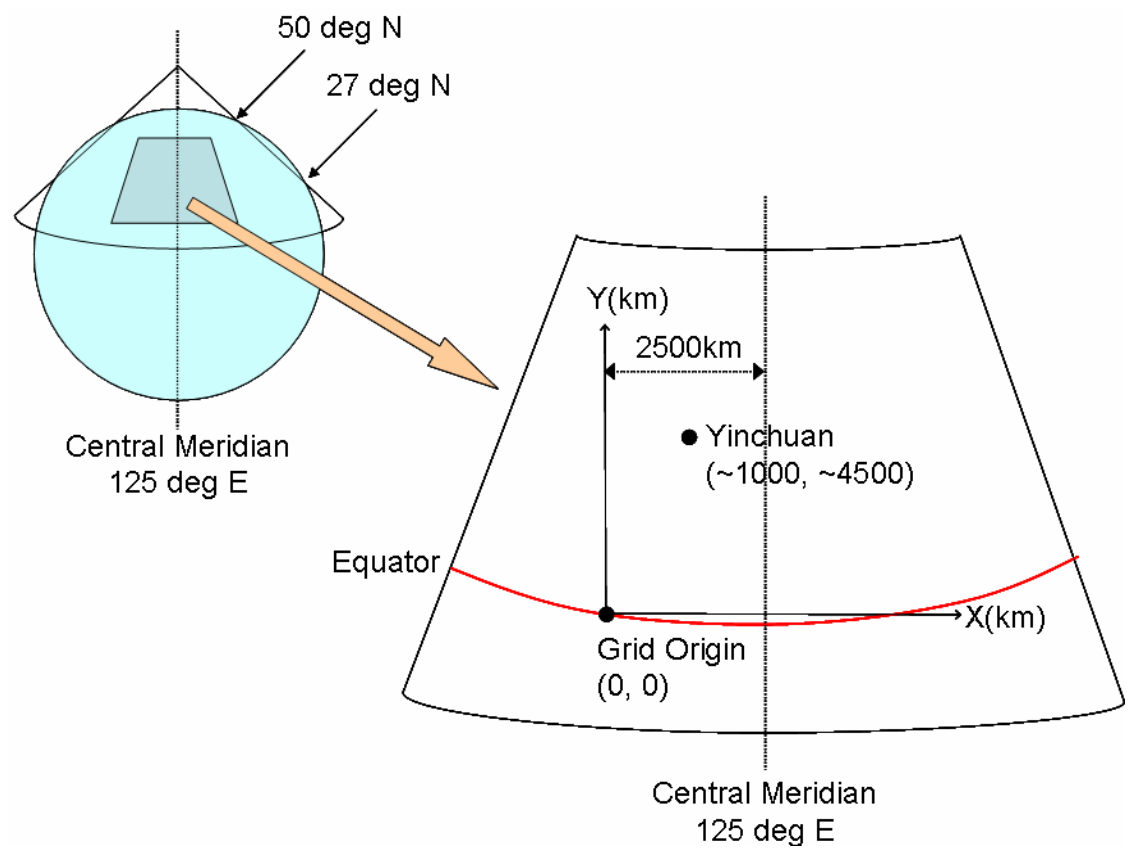

Figure A.1. Pictorial of Lambert Conformal Conic Projection for the Asian Study Area. Also shown is the convention for the coordinate system with a false origin $2500 \mathrm{~km}$ west of the central meridian and at the equator. Figure is from Hiroaki Terada of the Japan Atomic Energy Agency. 
Appendix B

Study-Region Climatology 



\section{Appendix B: Study-Region Climatology}

Tables B.1 and B.2 give the average monthly maximum temperature, minimum temperature, and average monthly rainfall throughout the Asian TEAM study area. Table B.1 gives November and December climatology, and Table B.2 gives March and April climatology. Figure B.1 shows the locations of the 14 cities with climatology listed in the tables.

Table B.1. November and December Climatology for Select Cities Throughout the Study Region. Given are the average maximum temperature $\left({ }^{\circ} \mathrm{C}\right)$, average minimum temperature $\left({ }^{\circ} \mathrm{C}\right)$, and average rainfall $(\mathrm{mm})$, respectively. The city locations shown in Figure 2.2 are identified by the number in the table. (Data source is http://uk.weather.com/, except for Seoul, which is http://www.climateandweather.com/.)

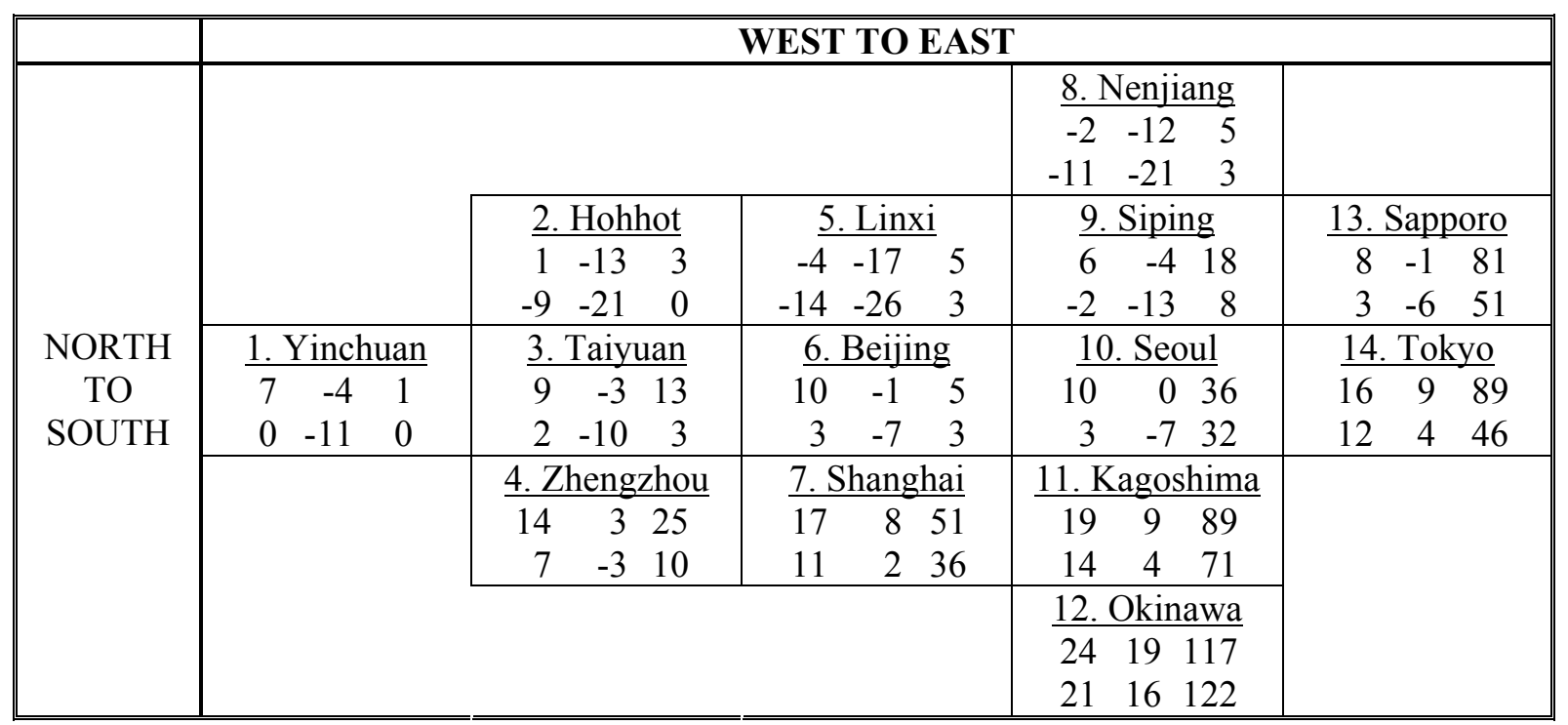


Table B.2. March and April Climatology for Select Cities Throughout the Study Region. Given are the average maximum temperature $\left({ }^{\circ} \mathrm{C}\right)$, average minimum temperature $\left({ }^{\circ} \mathrm{C}\right)$, and average rainfall $(\mathrm{mm})$, respectively. The city locations shown in Figure 2.2 are identified by the number in the table. (Data source is http://uk.weather.com/, except for Seoul, which is http://www.climateandweather.com/.)

\begin{tabular}{|c|c|c|c|c|c|}
\hline & \multicolumn{5}{|c|}{ WEST TO EAST } \\
\hline \multirow{13}{*}{$\begin{array}{l}\text { NORTH } \\
\text { TO } \\
\text { SOUTH }\end{array}$} & & & & \begin{tabular}{rrr}
\multicolumn{3}{r}{ 8. Nenjiang } \\
2 & -11 & 5 \\
13 & -1 & 15 \\
\end{tabular} & \\
\hline & & 2. Hohhot & 5. Linxi & 9. Siping & 13. Sapporo \\
\hline & & $\overline{4-12 \quad 4}$ & $-4-18 \quad 5$ & $\begin{array}{lll}6 & -4 & 15\end{array}$ & $\begin{array}{lll}3 & -4 & 53\end{array}$ \\
\hline & & $\begin{array}{lll}14 & -2 & 5\end{array}$ & $\begin{array}{lll}10 & -5 & 10 \\
\end{array}$ & $16 \quad 3 \quad 43$ & $\begin{array}{lll}8 & 1 & 91 \\
\end{array}$ \\
\hline & 1. Yinchuan & 3. Taiyuan & 6. Beijing & 10. Seoul & 14. Tokyo \\
\hline & $\begin{array}{lll}10 & -4 & 3\end{array}$ & $\begin{array}{lll}11 & -3 \quad 10\end{array}$ & $11 \quad-1 \quad 10$ & $\begin{array}{lll}8 & -2 & 56\end{array}$ & 12499 \\
\hline & $\begin{array}{lll}18 & 3 & 13\end{array}$ & 194 & $\begin{array}{lll}19 & 7 & 25\end{array}$ & 16568 & $\begin{array}{lll}18 & 10 & 124\end{array}$ \\
\hline & & 4. Zhengzhou & 7. Shanghai & 11. Kagoshima & \\
\hline & & $\begin{array}{lll}14225\end{array}$ & $\begin{array}{lll}12 & 5 & 81\end{array}$ & $\begin{array}{lll}16 & 6 & 160\end{array}$ & \\
\hline & & $21 \quad 9 \quad 48$ & $\begin{array}{lll}18 & 11 & 102\end{array}$ & $21 \quad 12 \quad 231$ & \\
\hline & & & & 12. Okinawa & \\
\hline & & & & $21 \quad 16163$ & \\
\hline & & & & $\begin{array}{lll}24 & 18 & 152\end{array}$ & \\
\hline
\end{tabular}




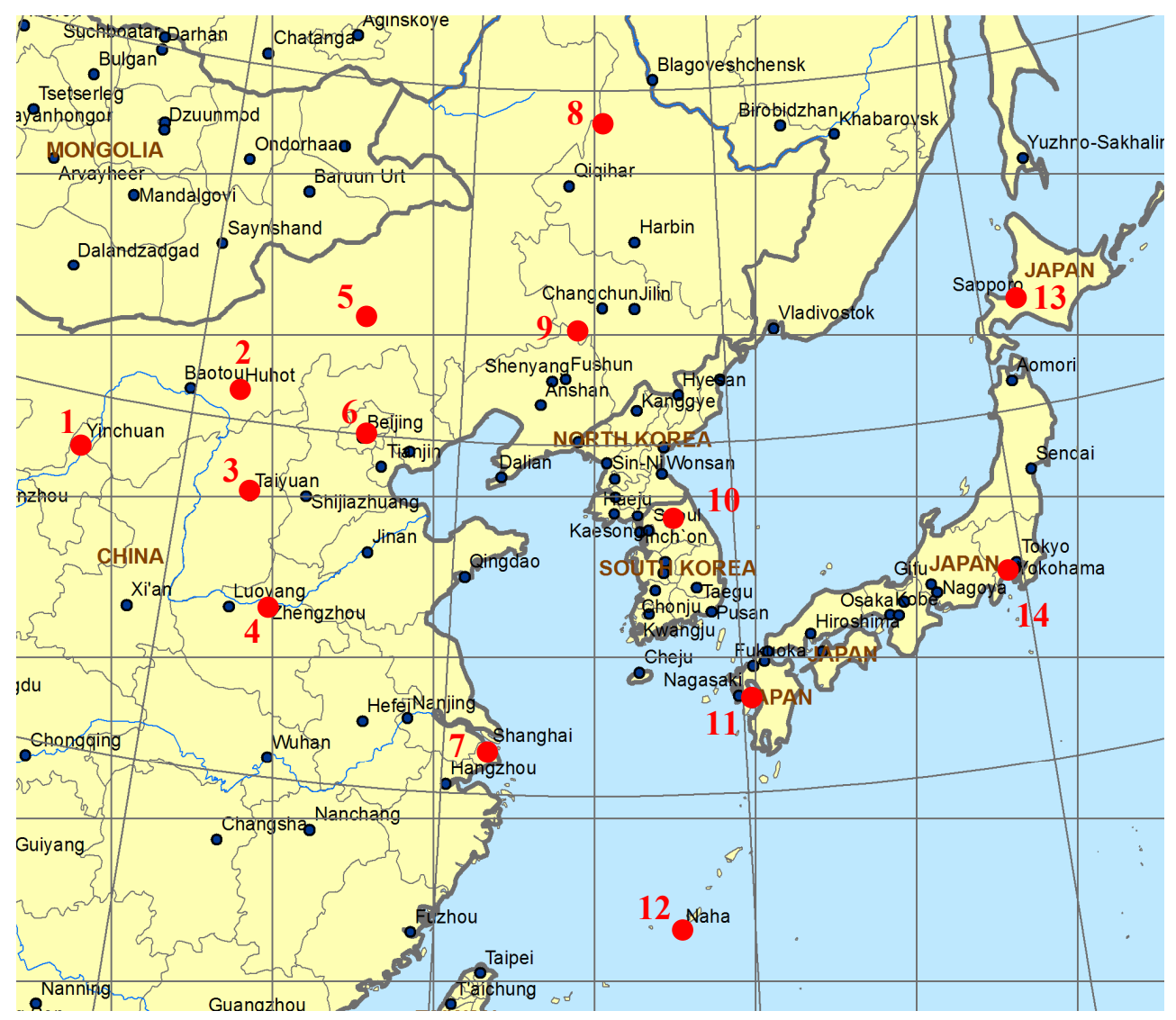

Figure B.1. Study Region Showing the Cities (red dots) with Climatology Information Given in Tables B.1 and B.2. The numbers correspond to the cities given in the tables. 



\section{Appendix C}

\section{Tracer Measurements Near Background}





\section{Appendix C: Tracer Measurements Near Background}

Considerable confusion arises when determining if tracer measurements near global background concentrations contain released tracer. Or, in other words, was the tracer plume actually detected? Ideally, determining if released tracer was detected at a location is straightforward, but in practice, it can be difficult, primarily because not all the uncertainties in the tracer sampling are properly accounted for. For example, PFT experiments measuring to global background levels require sample enhancement to occur, and the measure of the actual volume of air sampled generally has more uncertainty than desired. Another source of error is that passive sampling of the adsorption tubes can occur. If tracer samplers are deployed for several days, tracer material can adsorb in the sampling tubes even with no airflow.

The four most important parameters for interpreting tracer measurements $\left(\mathrm{C}_{\mathrm{m}}\right)$ at near global background concentrations are the average background concentration $\left(\mathrm{C}_{\mathrm{b}}\right)$, the standard deviation of the background concentration $\left(\mathrm{S}_{\mathrm{Cb}}\right)$, the method background precision $\left(\delta_{\mathrm{pb}}\right)$, and the method level of quantitation $\left(\delta_{\mathrm{q}}\right.$, commonly denoted as MLOQ). Typically, in tracer studies, $\mathrm{C}_{\mathrm{b}}$ and $\mathrm{S}_{\mathrm{Cb}}$ of the PFTs of interest are calculated over the duration of the tracer sampling period. The tracer plume concentrations $\left(\mathrm{C}_{\mathrm{a}}\right)$ at each measurement location are then determined as

$$
C_{a}=C_{m}-C_{b}
$$

and if $\mathrm{C}_{\mathrm{a}}$ is negative, then $\mathrm{C}_{\mathrm{a}}$ is set equal to zero. Using $\mathrm{S}_{\mathrm{Cb}}$ as a measure of the variation in background concentration, $\mathrm{C}_{\mathrm{a}}$ values less than or equal to $\mathrm{S}_{\mathrm{Cb}}$ cannot be considered as measures of the actual plume. $\delta_{\mathrm{pb}}$ is the precision in the measured concentration at concentration levels near background. Ideally, this would be determined by repeated sampling/analysis of a tracer standard near the background concentration. In all cases, $\delta_{\mathrm{pb}}$ should be less than or equal to $\mathrm{S}_{\mathrm{Cb}}$. In practice, $\delta_{\mathrm{pb}}$ is sometimes assumed to be $\mathrm{S}_{\mathrm{Cb}}$.

$\delta_{\mathrm{q}}$ (MLOQ) is defined as the lowest concentration that can be determined within $30 \%$ of the actual concentration and is calculated as 10 times the standard deviation of repeated sampling and analysis of a "low level" tracer standard. The standard concentration should be as low as possible and yet still meet the criteria where the signal-to-noise ratio (mean concentration/standard deviation) is between 3 and 10, and the fraction recovery (mean concentration/standard concentration) is between 0.9 and 1.1. The desire in tracer experiments is to have $\delta_{\mathrm{q}}$ much less than $\mathrm{C}_{\mathrm{b}}$, such that $\mathrm{C}_{\mathrm{b}}, \mathrm{S}_{\mathrm{Cb}}$, and $\delta_{\mathrm{pb}}$ can be accurately measured. However, in practice, $\delta_{\mathrm{q}}$ may be greater than $\mathrm{C}_{\mathrm{b}}$ (or $\delta_{\mathrm{q}}$ actually underestimated), such that discerning the actual tracer plume from background becomes much more uncertain and difficult.

We are not aware of any background measurements of PFTs in China; however, a study in South Korea (Kim et al. 2002) reports an average PMCH background concentration of $7.1 \mathrm{ppq}$ and a standard deviation of 0.8 ppq. Also, background concentrations of PMCP and PMCH were recently (May 2007) measured to be 6.5 and $6.8 \mathrm{ppq}$, respectively, in the southern portion of Japan (Kumamoto Prefecture) as mentioned in a personal communication with M. Chino (email dated June 26, 2007).

Now let's consider the design criteria for determining the release rate of $\mathrm{PMCH}$ needed to distinguish the tracer plume from background concentrations. Assume that the method background precision, $\delta_{\mathrm{pb}}$, is $\sim 0.1 \mathrm{ppq}, \mathrm{C}_{\mathrm{b}}$ is $6.8 \mathrm{ppq}$, and $\mathrm{S}_{\mathrm{Cb}}$ is $0.8 \mathrm{ppq}$. Consequently, for $\mathrm{C}_{\mathrm{a}}$ greater than $0.8 \mathrm{ppq}$, the tracer plume is 
present. So for design purposes, consider the minimum background-adjusted air concentration $\left(\mathrm{C}_{\mathrm{amin}}\right)$ for $\mathrm{PMCH}$ to be 1 ppq. As a comparison, $\mathrm{C}_{\mathrm{amin}}$ for oc-PDCH would be $0.1 \mathrm{ppq}$. This is based on a $\mathrm{C}_{\mathrm{b}}$ of $0.40 \mathrm{ppq}, \mathrm{a} \mathrm{S}_{\mathrm{Cb}}$ of $0.03 \mathrm{ppq}$, and a $\delta_{\mathrm{pb}}$ of approximately $0.01 \mathrm{ppq}$. The values for oc-PDCH are from ANATEX (Draxler et al. 1991).

It is critically important to note that the actual experimental $\delta_{\mathrm{q}}$ must be much less than $\mathrm{C}_{\mathrm{b}}$, or the design $\mathrm{C}_{\mathrm{amin}}$ values for determining release rates could easily be a factor of 10 higher. Additionally, when interpreting measured tracer values after an experiment, the low concentrations may not "make any sense" because of large uncertainty in the measured low values where the true uncertainty is not actually known because a robust value of $\delta_{\mathrm{q}}$ was not determined.

The typical analytical method for PFTs is based on gas chromatography using an electron capture detector (GC-ECD), and the necessary sampling method is to concentrate the sample onto an adsorbent within a small glass or metal tube during sample collection. By concentrating the sample, enough tracer mass can be accumulated from the ambient air to have a significant signal on the GE-ECD system, even for air at global background levels. For the current GC-ECD analytical systems and the sampling methods currently applied to PFT studies, $\delta_{\mathrm{q}}$ is controlled primarily by the volume of air sampled through the sampler adsorbent tubes. Generally, more air sampled provides more tracer mass for the analysis and thus a lower $\delta_{\mathrm{q}}$. The $\delta_{\mathrm{q}}$ values we expect to be attained by each of the TEAM tracer sampling/analysis teams (China, Japan, and the United States) are $\sim 0.1 \mathrm{ppq}$ or better for both PMCP and PMCH. If oc-PDCH were to be used as a tracer, we would expect a $\delta_{\mathrm{q}}$ value of $\sim 0.01 \mathrm{ppq}$ or better. Overall, we expect the sampling/analysis teams to provide tracer concentrations accurate to within $10 \%$ of the actual concentrations, even at background levels. 
Appendix D

\section{Simple Gaussian Puff Model}





\section{Appendix D: Simple Gaussian Puff Model}

Consider the Gaussian puff equation for material uniformly mixed in the vertical and the transport winds uniform with height:

$$
C_{A}(r, z ; H)=\left(\frac{22.696+0.083 T}{P M \times 10^{-15}}\right) \frac{Q}{2 \pi \sigma_{r} D} e^{-\frac{1}{2}\left(\frac{r}{\sigma_{r}}\right)^{2}}
$$

where $\mathrm{C}_{\mathrm{A}}=$ tracer concentration $(\mathrm{ppq})$

$\mathrm{Q}=$ tracer mass in puff $(\mathrm{kg})$

$\mathrm{D}=$ mixing depth $(\mathrm{km})$

$\sigma_{\mathrm{r}}=$ lateral dispersion parameter $(\mathrm{km})$

$\mathrm{r}=$ distance from puff center to receptor $(\mathrm{km})$

$\mathrm{z}=$ distance above ground and $<\mathrm{D}(\mathrm{km})$

$\mathrm{H}=$ height of release and $<\mathrm{D}(\mathrm{km})$

$\mathrm{P}=$ atmospheric pressure $(\mathrm{mb})$

$\mathrm{T}=$ air temperature $\left({ }^{\circ} \mathrm{C}\right)$

$\mathrm{M}=$ tracer molecular weight $\left(\mathrm{kg} \mathrm{kgmole}{ }^{-1}\right)$.

Equation (D.1) is solved by numerically stepping downwind from the release point in steps of $\delta \mathrm{x}$ $(\mathrm{km})$ and assuming winds of constant direction and speed, $\mathrm{U}\left(\mathrm{km} \mathrm{h}^{-1}\right)$. For a puff model to represent a continuous plume, the spacing between puffs must be less than $\sigma_{\mathrm{r}}$. Consequently, $\delta \mathrm{x}$ is set to be equal to a minimum $\sigma_{\mathrm{r}}$ determined as the $\sigma_{\mathrm{r}}$ at some distance from the release and still well upwind of the downwind distance of the first desired calculated concentration. The model time step $\delta \mathrm{t}(\mathrm{h})$ is determined as

$$
\delta t=\frac{\delta x}{U}
$$

The lateral dispersion coefficient, $\sigma_{\mathrm{r}}(\mathrm{km})$, is determined from the following formulation by Heffter (1965), approximating long-range tropospheric dispersion:

$$
\sigma_{r}=\left(\frac{3600}{1000}\right) \frac{1}{2} t
$$

where $t$ is the puff travel time ( $h$ ) and is calculated as the puff downwind distance divided by $\mathrm{U}$. The tracer mass per puff ( $\mathrm{Q}$ in Equation D.1) is determined as

$$
Q=\delta t Q_{R}
$$


where $Q_{R}$ is the tracer release rate $\left(\mathrm{kg} \mathrm{h}^{-1}\right)$. The number of puffs, $\mathrm{N}_{\mathrm{p}}$, representing the released tracer plume is computed as

$$
N_{p}=\frac{\Delta t_{R} U}{\delta x}
$$

where $\Delta t_{R}$ is the duration of the tracer release $(h)$.

A check on the proper operation of the puff model can be accomplished using the Gaussian plume equation for a continuous release:

$$
C_{A}(x, y, z ; H)=\left(\frac{22.696+0.083 T}{P M \times 10^{-15}}\right) \frac{Q_{R}}{\sqrt{2 \pi} U \sigma_{y} D} e^{-\frac{1}{2}\left(\frac{y}{\sigma_{y}}\right)^{2}}
$$

$$
\text { where } \begin{aligned}
\mathrm{C}_{\mathrm{A}}= & \text { tracer concentration }(\mathrm{ppq}) \\
\mathrm{Q}_{\mathrm{R}}= & \text { tracer release rate }\left(\mathrm{kg} \mathrm{h}^{-1}\right) \\
\mathrm{D} & \text { mixing depth }(\mathrm{km}) \\
\mathrm{U} & \text { wind speed }\left(\mathrm{km} \mathrm{h}^{-1}\right) \\
\sigma_{\mathrm{y}} & \text { lateral dispersion parameter }(\mathrm{km}) \\
\mathrm{y} & \text { crosswind distance to receptor }(\mathrm{km}) \\
\mathrm{Z} & \text { distance above ground and }<\mathrm{D}(\mathrm{km}) \\
\mathrm{H} & \text { height of release and }<\mathrm{D}(\mathrm{km}) \\
\mathrm{P} & =\text { atmospheric pressure }(\mathrm{mb}) \\
\mathrm{T} & =\text { air temperature }\left({ }^{\circ} \mathrm{C}\right) \\
\mathrm{M} & =\text { tracer molecular weight }\left(\mathrm{kg} \mathrm{kgmole}{ }^{-1}\right) .
\end{aligned}
$$

The lateral dispersion parameter is determined using Equation D.3. It is interesting to note that for Heffter's form of the lateral dispersion coefficient, Equation D. 6 becomes independent of wind speed. That is, for all downwind distances, the concentration is only a function of the tracer release rate and mixing depth. 


\section{Appendix E}

Winds from Central China to Central Japan 



\section{Appendix E: Winds from Central China to Central Japan}

This appendix gives time series plots of surface and upper air winds for five weather stations in China and one station in Japan. The plots are for April and December of 2003. Wind direction plots include a 45-degree band in yellow that represents the wind directions that would be favorable for plume transport from central China toward Japan. Figure E.1 shows the locations of the six weather stations, and Table E.1 gives the elevations of the weather stations.

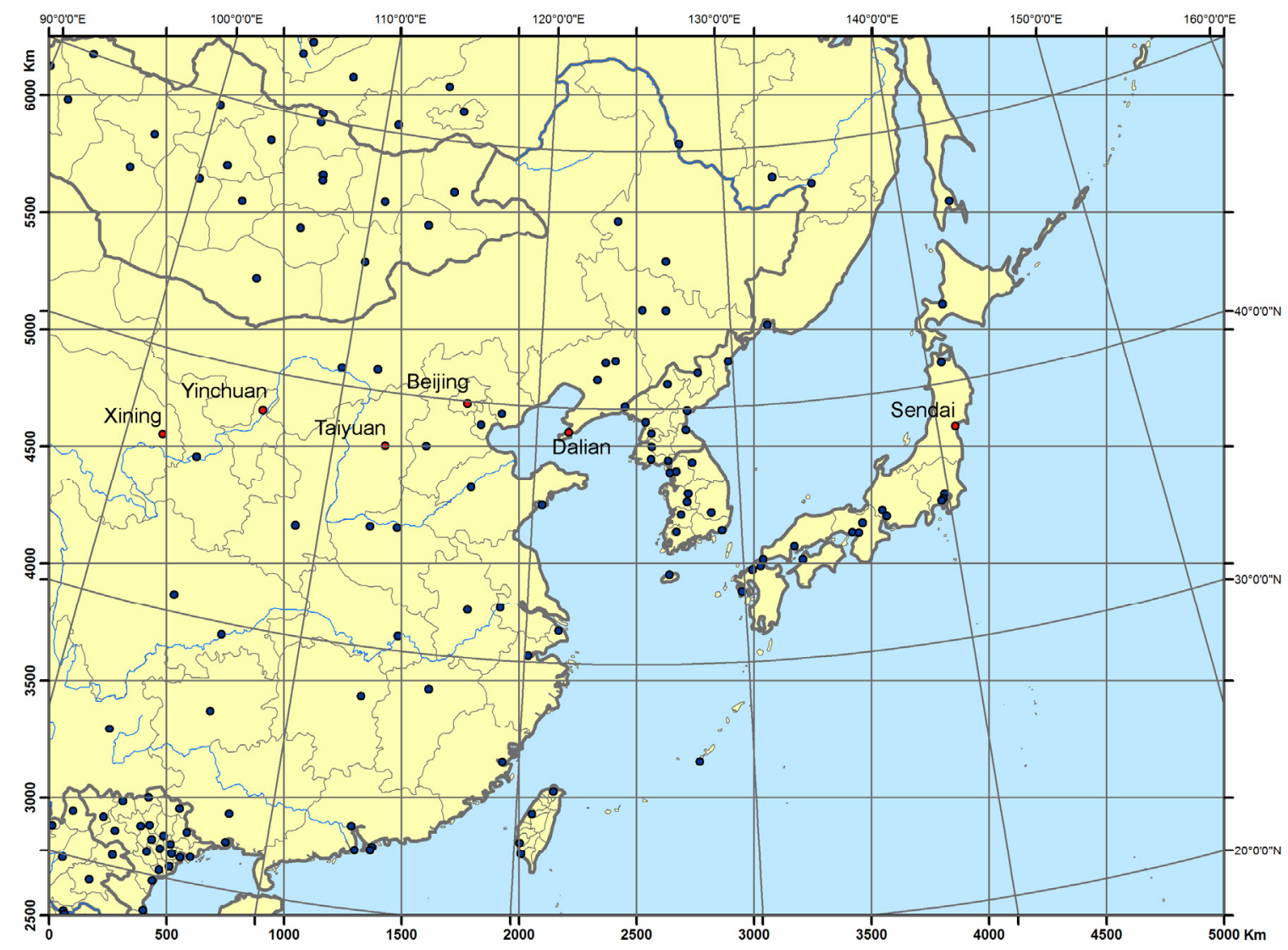

Figure E.1. Map Showing the Cities (red markers) with Surface Data and Upper Air Data that Are Plotted in Subsequent Figures

Table E.1. Elevations ( $m$ above mean sea level [MSL]) of the Five Weather Stations in China and the One Weather Station in Japan with Data Given in the Subsequent Figures

\begin{tabular}{|l|c|}
\hline Station Location & Elevation (m) \\
\hline \hline Xining, China & 2300 \\
\hline Yinchuan, China & 1110 \\
\hline Taiyuan, China & 780 \\
\hline Beijing, China & 550 \\
\hline Dalian, China & 970 \\
\hline Sendai, Japan & 430 \\
\hline
\end{tabular}



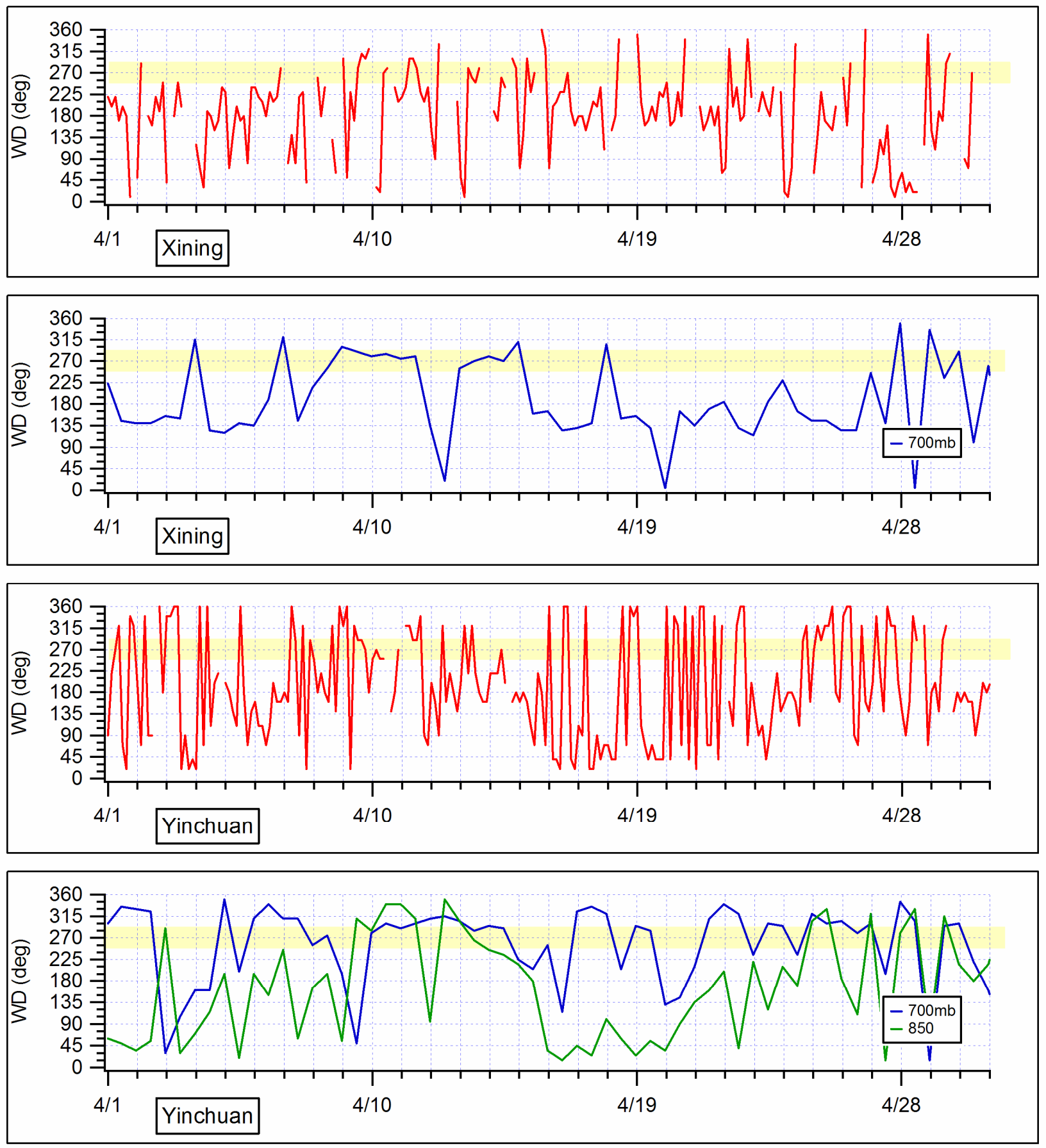

Figure E.2. Wind Directions Measured Near Xining and Yinchuan, China, During April 2003. The panels with the red lines represent surface measurements, while the green and blue lines represent $850-\mathrm{mb}$ and $700-\mathrm{mb}$ measurements, respectively. 

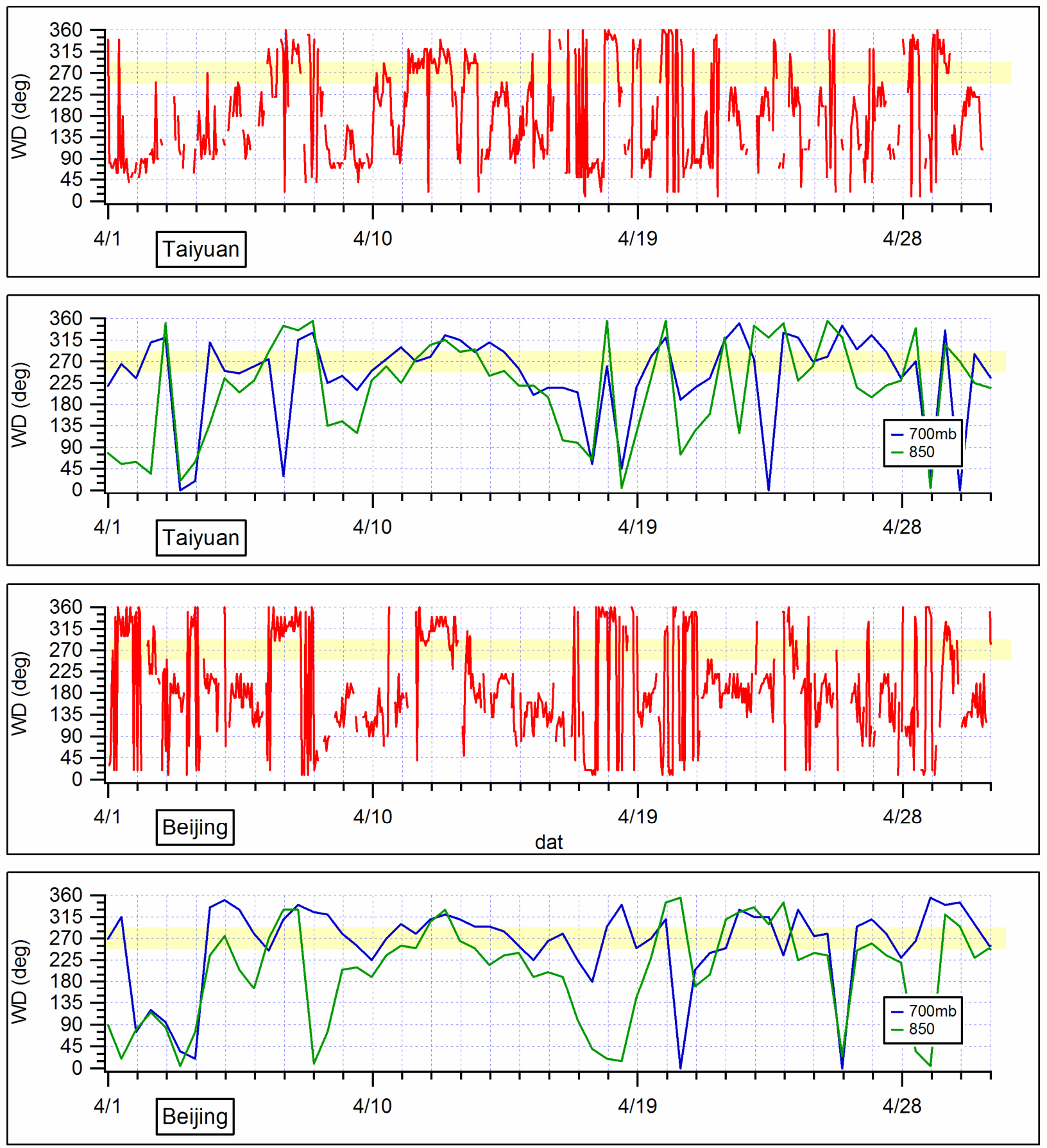

Figure E.3. Wind Directions Measured Near Taiyuan and Beijing, China, During April 2003. The panels with the red lines represent surface measurements while the green and blue lines represent $850-\mathrm{mb}$ and $700-\mathrm{mb}$ measurements, respectively. 

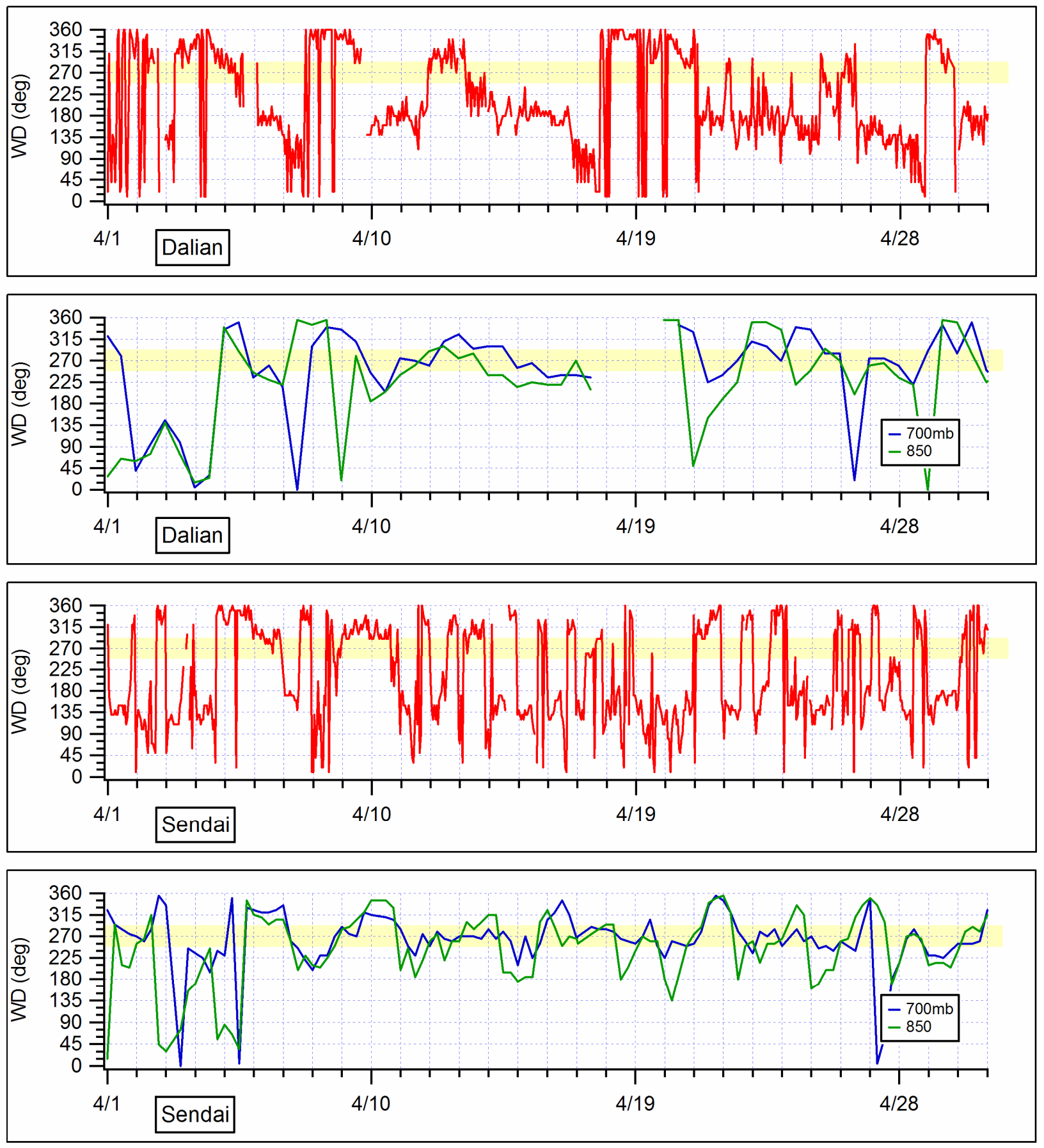

Figure E.4. Wind Directions Measured near Dalian, China, and Sendai, Japan, During April 2003. The panels with the red lines represent surface measurements while the green and blue lines represent $850-\mathrm{mb}$ and $700-\mathrm{mb}$ measurements, respectively. 

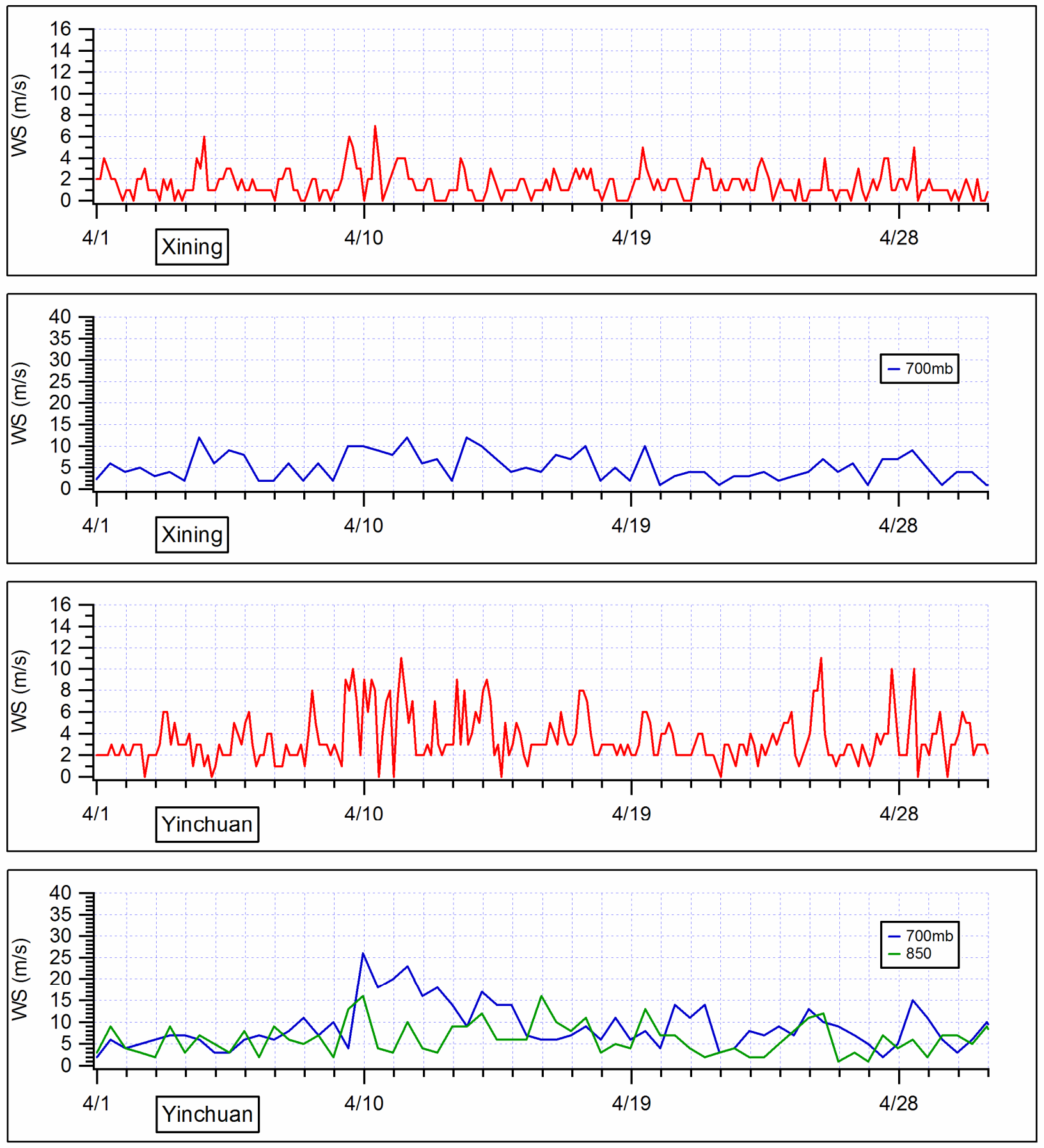

Figure E.5. Wind Speeds Measured Near Xining and Yinchuan, China, During April 2003. The panels with the red lines represent surface measurements while the green and blue lines represent 850-mb and 700-mb measurements, respectively. 

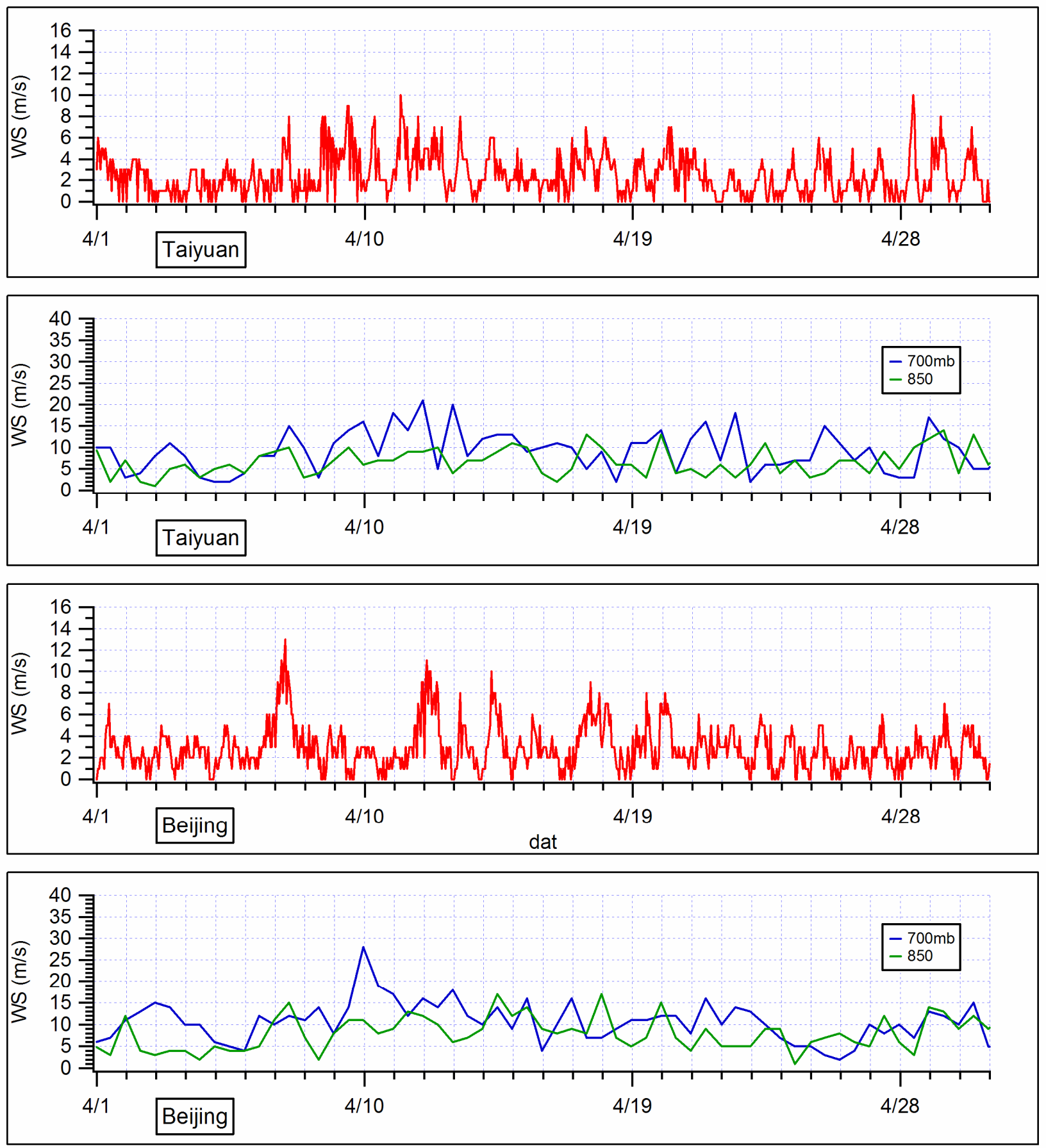

Figure E.6. Wind Speeds Measured Near Taiyuan and Beijing, China, During April 2003. The panels with the red lines represent surface measurements, while the green and blue lines represent 850-mb and 700-mb measurements, respectively. 

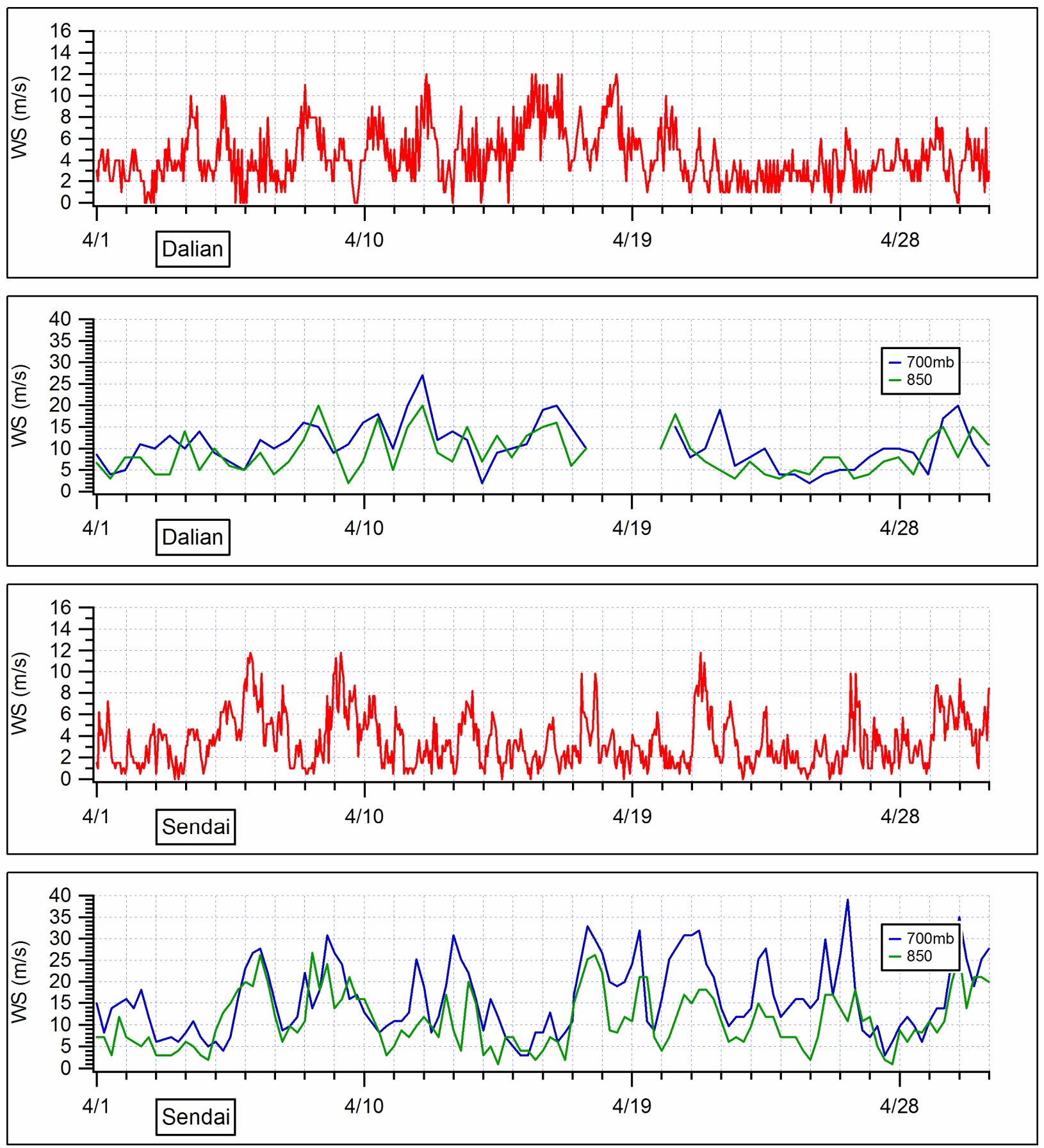

Figure E.7. Wind Speeds Measured Near Dalian, China, and Sendai, Japan, During April 2003. The panels with the red lines represent surface measurements while the green and blue lines represent $850-\mathrm{mb}$ and $700-\mathrm{mb}$ measurements, respectively. 

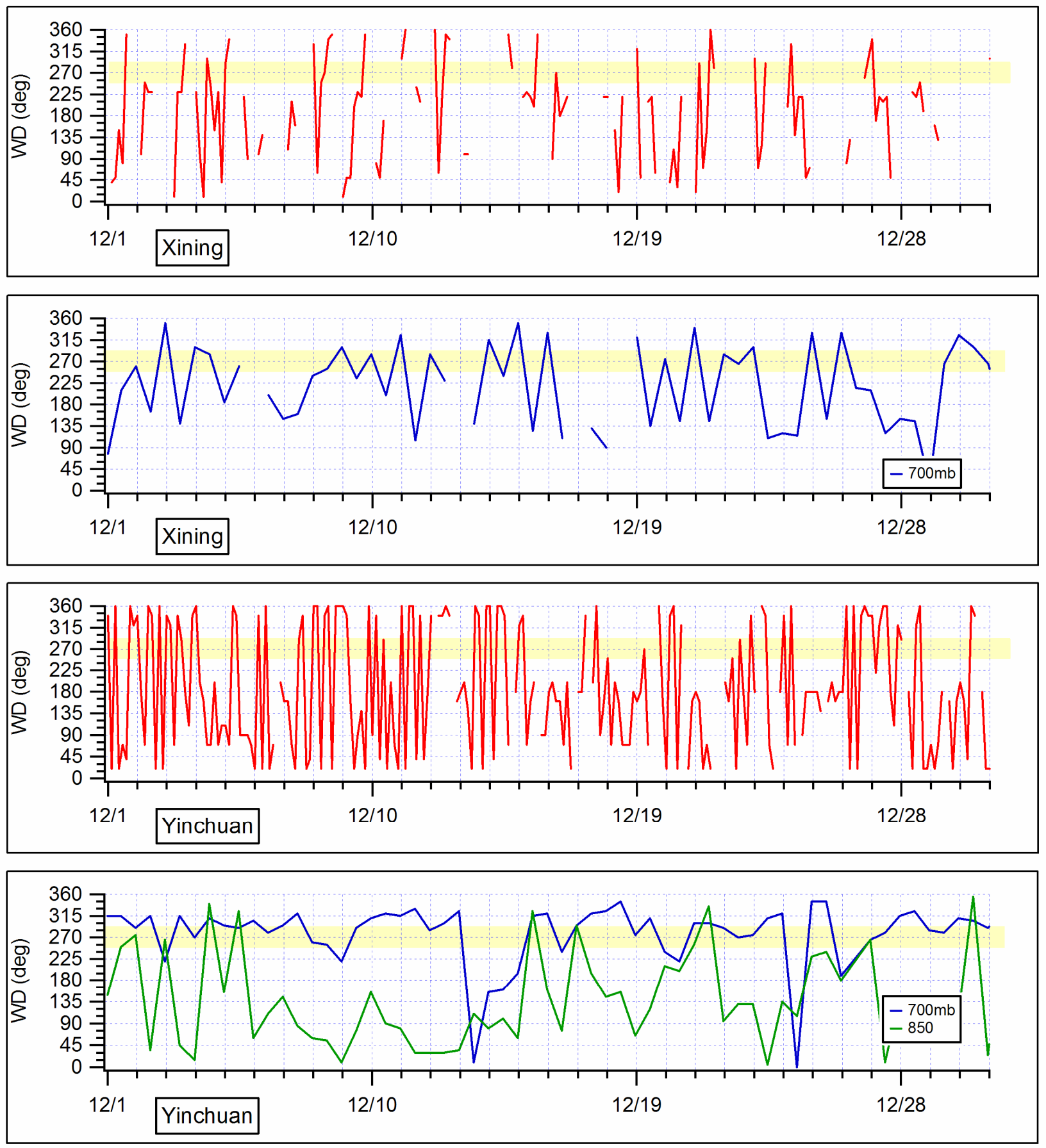

Figure E.8. Wind Directions Measured Near Xining and Yinchuan, China, During December 2003. The panels with the red lines represent surface measurements while the green and blue lines represent $850-\mathrm{mb}$ and $700-\mathrm{mb}$ measurements, respectively. 

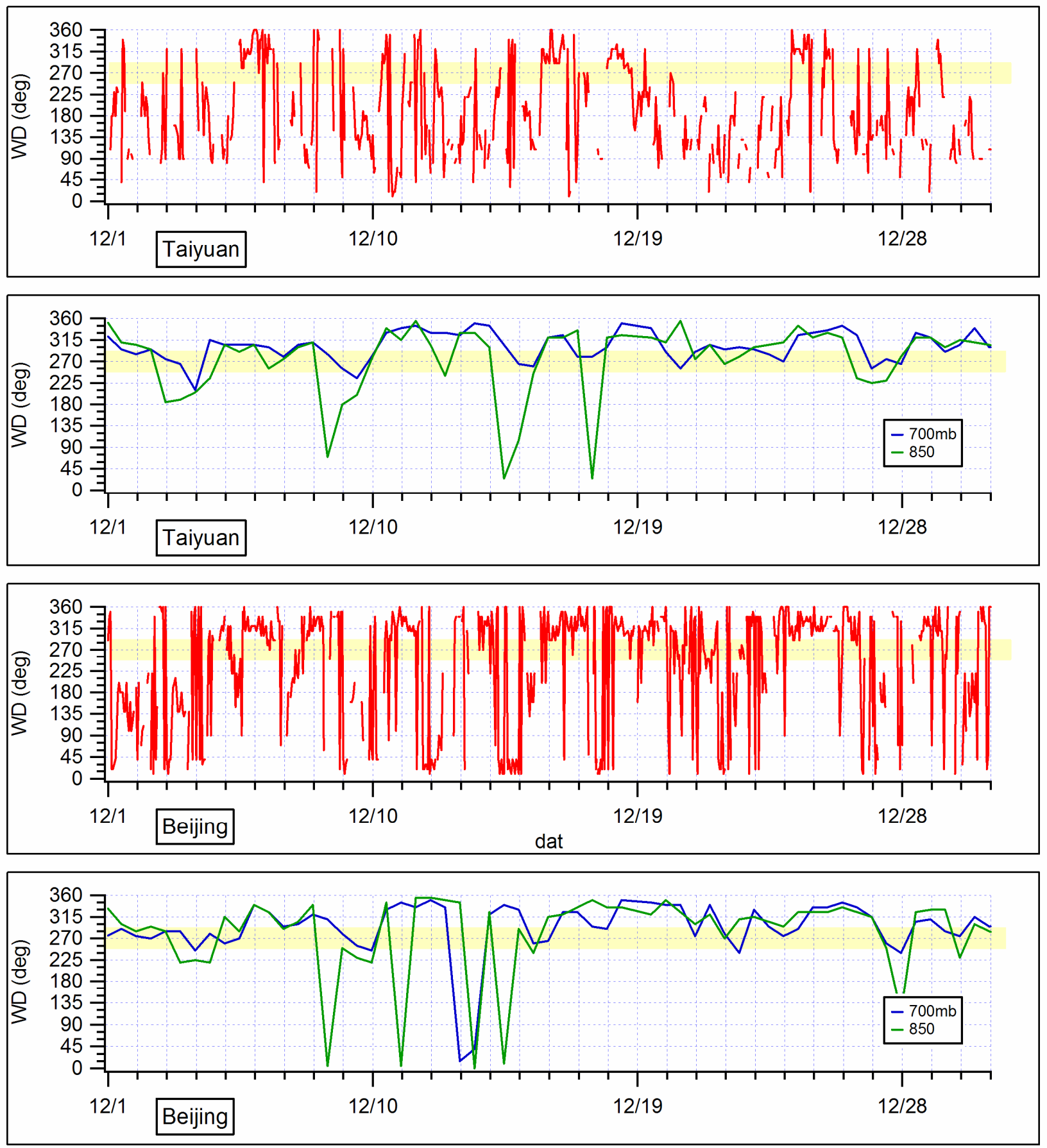

Figure E.9. Wind Directions Measured Near Taiyuan and Beijing, China, During December 2003. The panels with the red lines represent surface measurements while the green and blue lines represent $850-\mathrm{mb}$ and $700-\mathrm{mb}$ measurements, respectively. 

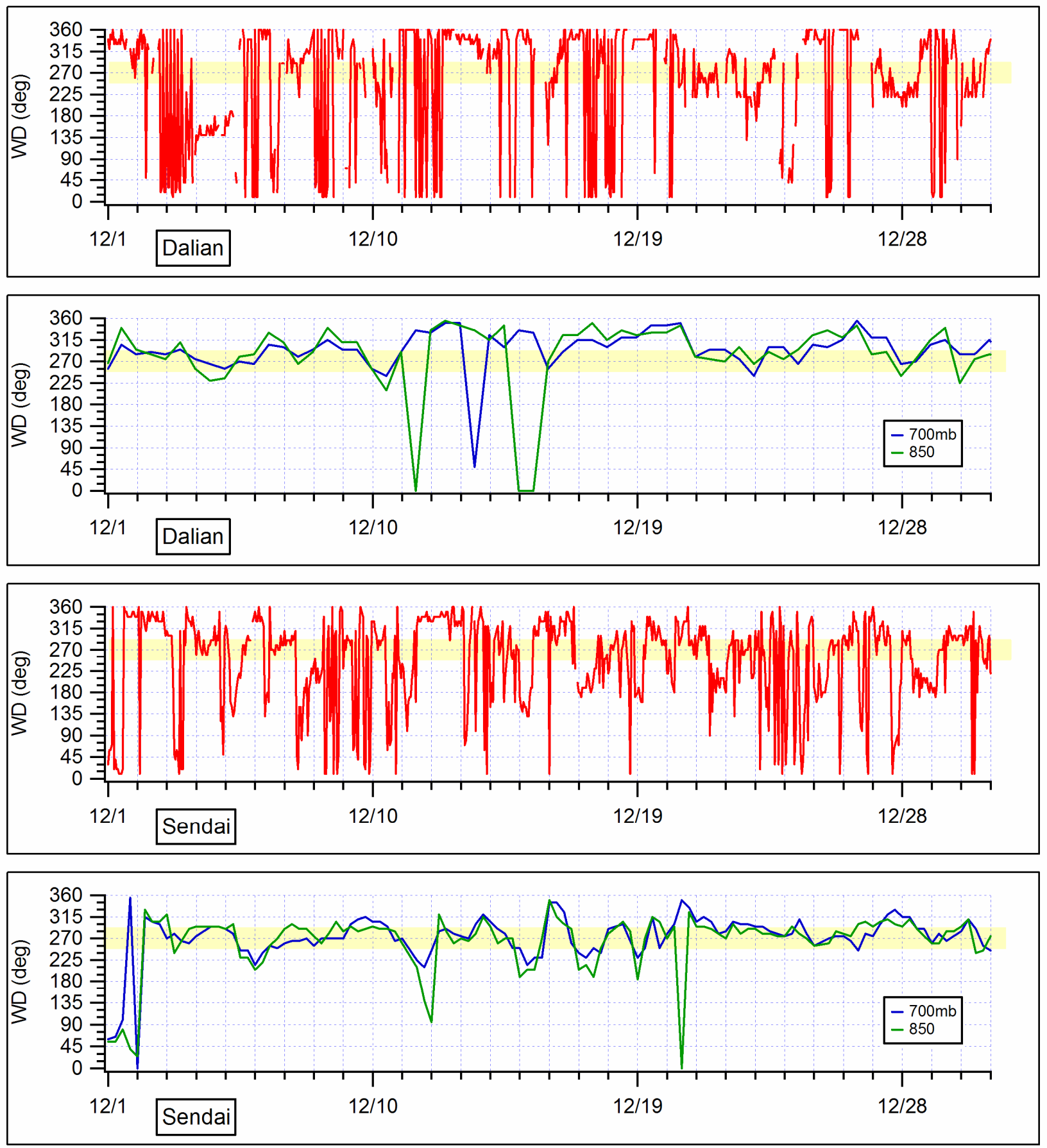

Figure E.10. Wind Directions Measured Near Dalian, China, and Sendai, Japan, During December 2003. The panels with the red lines represent surface measurements while the green and blue lines represent 850-mb and 700-mb measurements, respectively. 

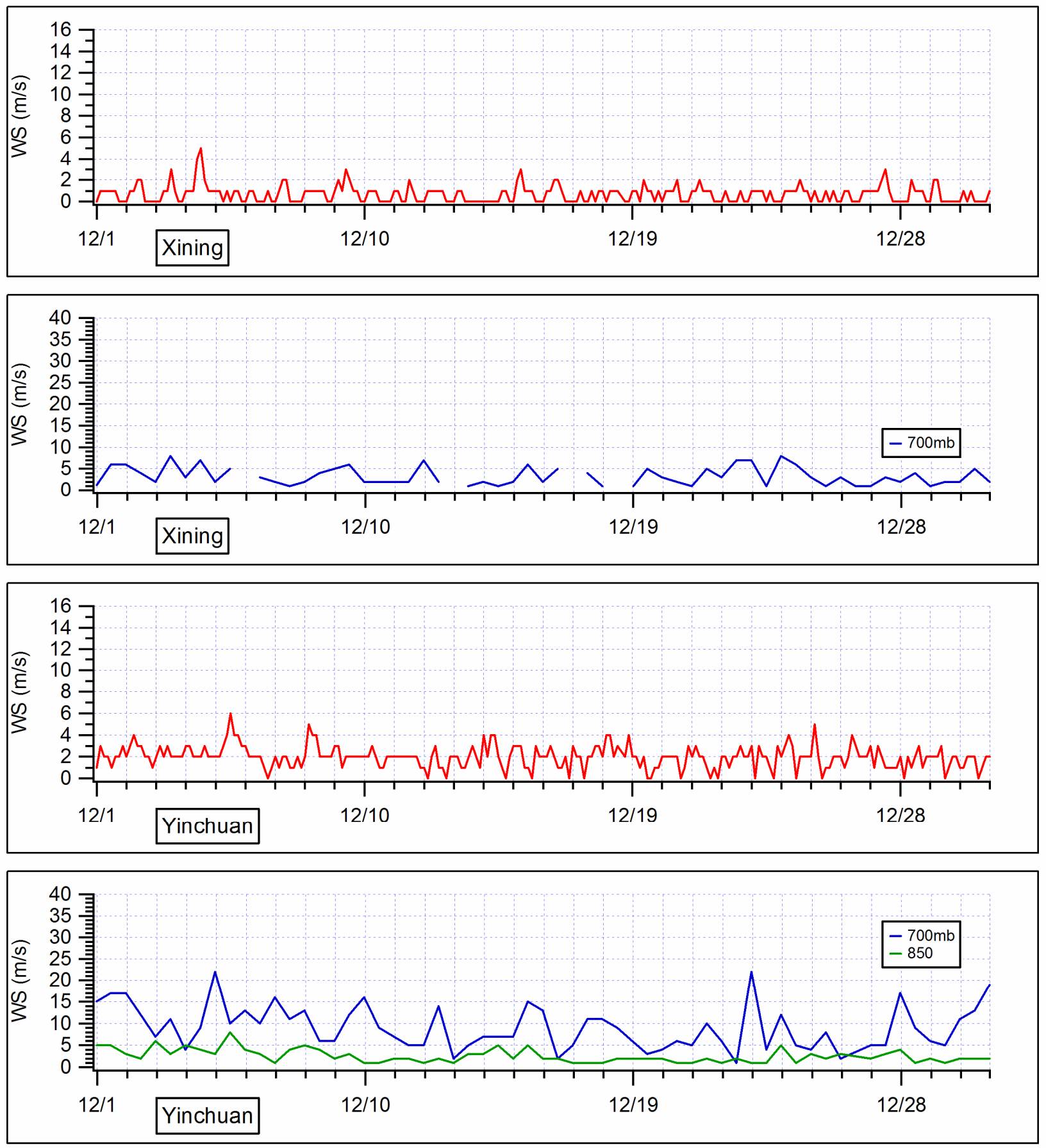

Figure E.11. Wind Speeds Measured Near Xining and Yinchuan, China, During December 2003. The panels with the red lines represent surface measurements while the green and blue lines represent $850-\mathrm{mb}$ and $700-\mathrm{mb}$ measurements, respectively. 

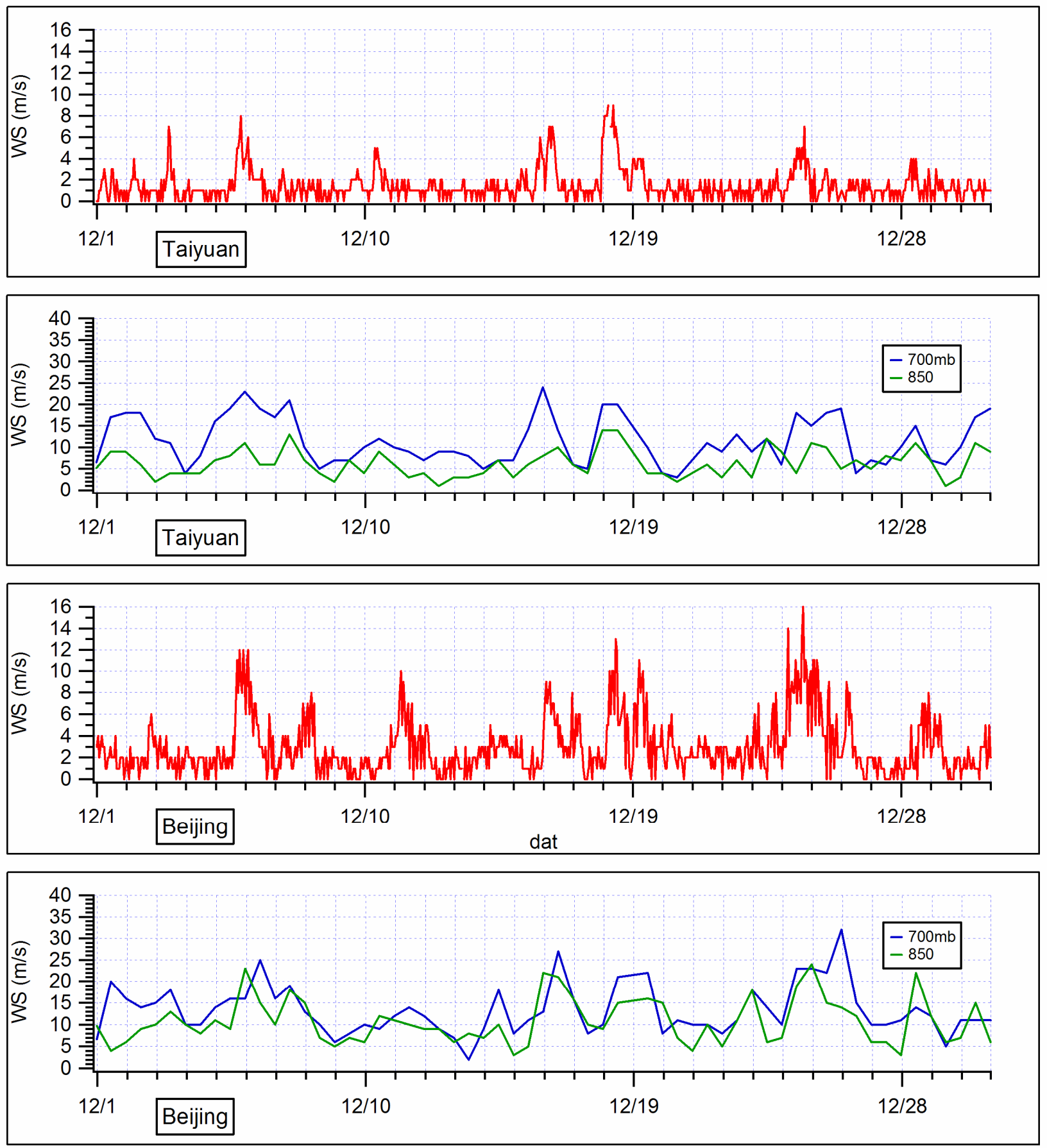

Figure E.12. Wind Speeds Measured Near Taiyuan and Beijing, China, During December 2003. The panels with the red lines represent surface measurements while the green and blue lines represent $850-\mathrm{mb}$ and $700-\mathrm{mb}$ measurements, respectively. 

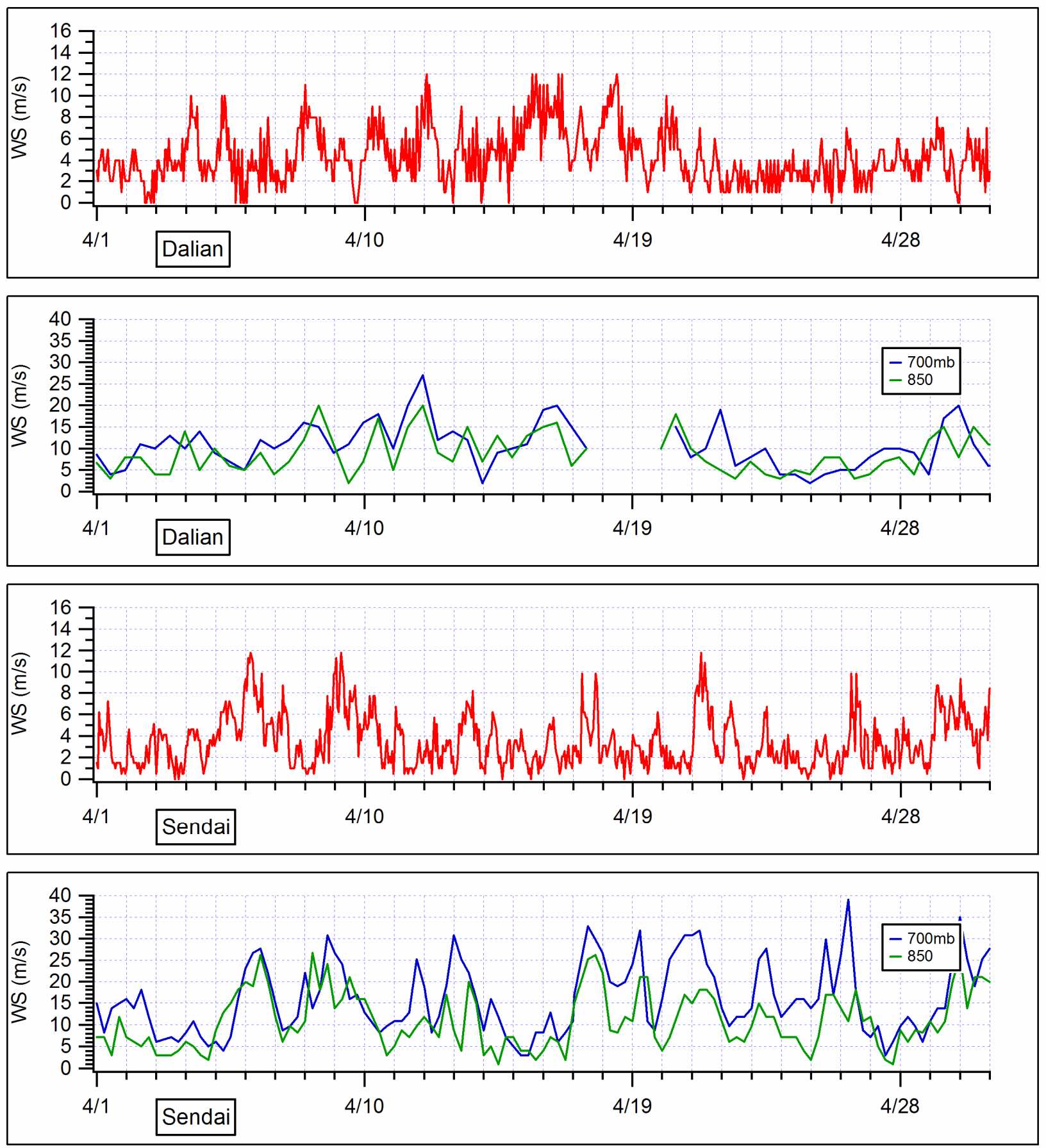

Figure E.13. Wind Speeds Measured Near Dalian, China, and Sendai, Japan, During December 2003. The panels with the red lines represent surface measurements while the green and blue lines represent 850-mb and 700-mb measurements, respectively. 



\section{Distribution}

No. of

Copies

\section{OFFSITE}

1 Vince McClelland

U.S. Department of Energy

Office of International Emergency Management and

Cooperation

NA-23/L'Enfant Plaza

1000 Independence Ave., S.W.

Washington, DC 20585-1615

1 Michael M. Bradley, L-103

Lawrence Livermore National Laboratory

P.O. Box 808

Livermore, CA 94551

\section{ONSITE}

11 Pacific Northwest National Laboratory

K. J. Allwine (7) K9-30

J. E. Flaherty K9-30

J. K. Ace K6-68

Information Release (2) P8-55

Distr. 1 